\title{
The interplay between societal concerns and the regulatory frame on GM crops in the European Union
}

\author{
Yann DEVOS ${ }^{1 *}$, Dirk REHEUL ${ }^{1}$, Danny DE WAELE² and Linda VAN SPEYBROECK ${ }^{2}$ \\ ${ }^{1}$ Department of Plant Production, Faculty of Bioscience Engineering, Ghent University, Coupure Links 653, 9000 Ghent, Belgium \\ ${ }^{2}$ Centre for Critical Philosophy, Department of Philosophy and Moral Science, Ghent University, Blandijnberg 2, 9000 Ghent, Belgium
}

Recapitulating how genetic modification technology and its agro-food products aroused strong societal opposition in the European Union, this paper demonstrates how this opposition contributed to shape the European regulatory frame on GM crops. More specifically, it describes how this opposition contributed to a de facto moratorium on the commercialization of new GM crop events in the end of the nineties. From this period onwards, the regulatory frame has been continuously revised in order to slow down further erosion of public and market confidence. Various scientific and technical reforms were made to meet societal concerns relating to the safety of GM crops. In this context, the precautionary principle, environmental post-market monitoring and traceability were adopted as ways to cope with scientific uncertainties. Labeling, traceability, co-existence and public information were installed in an attempt to meet the general public request for more information about GM agro-food products, and the specific demand to respect the consumers' and farmers' freedom of choice. Despite these efforts, today, the explicit role of public participation and/or ethical consultation during authorization procedures is at best minimal. Moreover, no legal room was created to progress to an integral sustainability evaluation during market procedures. It remains to be seen whether the recent policy shift towards greater transparency about value judgments, plural viewpoints and scientific uncertainties will be one step forward in integrating ethical concerns more explicitly in risk analysis. As such, the regulatory frame stands open for further interpretation, reflecting in various degrees a continued interplay with societal concerns relating to GM agro-food products. In this regard, both societal concerns and diversely interpreted regulatory criteria can be inferred as signaling a request - and even a quest - to render more explicit the broader-than-scientific dimension of the actual risk analysis.

Keywords: Co-existence / de facto moratorium / ethics / genetically modified crops / labeling / post-market monitoring / precautionary principle / public participation / societal concerns / sustainability

\section{INTRODUCTION}

Compared to any other recent agricultural advance, genetically modified (GM) agro-food products induced a broad and intensive societal opposition in the European Union (EU). Even nowadays, the latest Eurobarometer survey shows that "GM food is widely seen as not being useful, as morally unacceptable and as a risk for society" (Gaskell et al., 2006). This opposition signals a request and even a quest - to render more explicit the broaderthan-scientific dimension of the actual risk analysis of GM agro-food products. Scientifically trained experts and lay people are known to perceive risks differently (Marris et al., 2001; Slovic, 1987; Wynne, 2001). Experts tend

\footnotetext{
*Corresponding author: Yann.Devos@UGent.be
}

to describe risks in objective and factual terms, whilst lay people widely complement the concept of risk with concerns about usefulness, socio-economic impacts, freedom of choice, unnaturalness of genetic modification, respect for nature, long-term and irreversible consequences, democracy, disparities between the industrialized world and the third world, scientific uncertainties, fallibility of experts, uncontrollability and/or sustainability of agriculture (Cook et al., 2004; Deckers, 2005; Frewer et al., 2004; Lassen and Jamison, 2006; Lassen et al., 2002; Madsen and Sandøe, 2005; Shaw, 2002; Townsend, 2006; Verhoog et al., 2003). In the EU, this difference in risk perception contributed to a public distrust towards scientists, policy makers and regulatory procedures (Frewer et al., 2004; Marris et al., 2001; Siegrist, 2000). To slow down further growth of this distrust, various researchers 
Y. Devos et al.

recommended (1) to make scientific opinions more transparent by denoting explicitly the factual and normative premises on which they are based; (2) to allow the contribution of diverse publics in the processes of risk analysis by organizing participatory exercises; and/or (3) to implement an integral sustainability evaluation that integrates societal concerns by, for instance, weighing of possible risks and benefits, comparing technological alternatives, testing the usefulness or assessing the whole agricultural system (ACRE, 2006; COGEM, 2003; Deblonde and du Jardin, 2005; Frewer et al., 2004; Genus and Coles, 2005; Irwin, 2006; Jensen and Sandøe, 2002; Krayer von Krauss et al., 2004; Mayer and Stirling, 2002; Nielsen and Faber, 2002; Nowotny, 2003; Schot, 2001; Wandall, 2004). In practice, as a response to the societal opposition towards GM agro-food products, a de facto moratorium on the commercialization of new GM crop events was put in place in the EU from 1999 to 2004. During this moratorium the regulatory frame on GM crops was thoroughly revised in order to improve public and market confidence. Specific values, norms, criteria and principles already present in the regulatory frame were strengthened, whilst new ones were implemented.

Exploring these events in detail via a historical reconstruction, this paper illustrates how GM crops destined for food, feed, cultivation, import, industrial processing and/or experimental purposes aroused considerable societal opposition in the EU. We will discuss how this opposition contributed to shape the European regulatory frame on GM agro-food products. Hence, the European GM crop legislation would have taken another path in the absence of societal contestation. We will discuss whether and which societal concerns were implemented explicitly or implicitly, how their expression and meaning evolved, and how some of these legal criteria are translated in practice. Finally, we will consider to what extent the established regulatory frame, which became one of the most stringent regimes in the world, will be helpful in pacifying the conflict in the EU and which concerns currently fall out of the regulatory scope.

\section{RISK ANALYSIS OF GM CROPS}

In the EU, the use of GM crops for food, feed, cultivation, import, industrial processing and/or experimental purposes is subjected to a risk analysis prior to use. Risk analysis is a process consisting of three interrelated components: risk assessment, risk management and risk communication. In risk assessment, potential adverse impacts associated with a specific activity are scientifically characterized. In risk management, policy alternatives to accept, minimize or reduce the characterized risks are weighed and, if needed, appropriate prevention and control options are selected. Risk communication is generally defined as an interactive exchange of information and opinions on risk throughout risk analysis, running between risk assessors, risk managers and other interested parties. It includes the explanation of risk assessment findings and of the basis on which risk management decisions are made (EFSA, 2004b; Johnson et al., 2007).

In theory, there is a functional and temporal separation between risk assessment and risk management in order to reduce any conflict of interest and to protect the scientific integrity of risk assessment (de Sadeleer, 2006). Most societal concerns arising from the use of GM crops fall beyond the scope of risk assessment (which comes first in the process of risk analysis). They are at best debated elsewhere in specifically established ad hoc committees with appropriate expertise or in participatory initiatives usually organized by Technology Assessment bodies (Carr and Levidow, 2000; Genus and Coles, 2005; Irwin, 2006; Nielsen and Faber, 2002; Schot, 2001). As a result, most societal concerns generally are at play only in risk management, after a risk assessment has been done. In this view, risk assessment is depicted as a sound, science-based and objective approach to assess the safety of genetically modified organisms (GMOs), which leaves no space for values (Johnson et al., 2007).

However, in practice, values appear to be inherent to risk assessment, since there is a permanent interplay between risk assessment and risk management (de Sadeleer, 2006; Jensen and Sandøe, 2002; Levidow et al., 2005; Nielsen and Faber, 2002; Wandall, 2004; Wynne, 2001). This implicitly integrates an ethical perspective to the scientific view on risk assessment. Value judgments are required to characterize risks and to determine the acceptability of health and environmental impacts. Judgments are made about which kinds of harm to assess or ignore and about what baseline of comparison to use for assessing the severity and acceptability of risks (Carr, 2002). In the words of Jensen et al. (2003), "risk assessment views the world through a risk window that only makes visible what has been predefined as a relevant risk, and the size and structure of this window is determined by value judgments as to what is considered to be an adverse effect within what is considered the relevant horizon of time and space". It means that scientific data and procedures used in risk assessment fit into an evolving normative frame of values, norms, criteria and principles, partially set by legislation. In this way, the regulatory frame - that is the product of processes in democratic political systems - functions as a moral guide in risk assessment. Values also enter into risk assessment through a number of scientific methodological choices that are made to describe the world and map its consequences (Jensen and Sandøe, 2002; Murphy et al., 2006; Nielsen and Faber, 2002; Wandall, 2004). 
Societal concerns and EU regulatory frame on GM crops

\section{FIRST WAVE OF EUROPEAN LEGISLATIONS ON GM CROPS}

Because the techniques used for genetic modification were new and raised specific safety concerns, a processbased regulatory supervision of GMOs was deemed necessary in the EU (Guehlstorf and Hallstrom, 2005; Murphy et al., 2006). Similar safety concerns led to a resolution of the European Parliament in the eighties, calling for a ban on the deliberate release of GMOs, as long as binding legislations covering these releases were not in place in Europe. In the summer of 1987, the European Community legislative process with regard to genetic engineering legislation went into full swing, leading to the adoption of two European Directives in the early nineties. In this period, the first GM plants were released in the field for experimental purposes. At the same time, technology-specific legislation was established in some Member States (MS) such as Denmark and Germany. According to Gottweis (2005), these legal evolutions at the EU level also "reflected the new dynamics of the EU political system after the passing of the 1987 Single European Act, the rise of the European regulatory state, and the new importance of the environment as a core value in European policy making".

To avoid unequal competition and impediments between and within MS, and to stimulate scientific research and innovation, the European Commission (EC) promoted the development of a transparent and Europeanwide harmonization of GM crop legislations between MS. This led to the creation of an internal market that makes the free movement of GM agro-food products possible in the EU. Other legal objectives included (1) ensuring a high level of protection of human health, animal health and the environment; (2) enabling consumers and farmers to exercise effectively their freedom of choice in the market place; and (3) not misleading consumers and users (Christoforou, 2004).

\section{Directive $90 / 220$ on the deliberate release into the environment of genetically modified organisms}

From 1990 on, the contained use of GMOs was regulated by Directive 90/219. Directive 90/220 regulated their deliberate release into the environment, covering both the release for research purposes (part B) and for commercial use as or in products (part C). This regulatory triad reflects the stepwise commercial process transgenic crops go through, beginning with experiments under contained use (e.g. laboratory, greenhouse) through experimental release, up to the placing on the market.

Once Directive 90/220 was in force, the first market consents were granted in the EU. The kick off was given in 1994 by the approval of the cultivation of the transgenic tobacco event ITB1000OX. The first GM product to be effectively released on the European market was paste from the Flavr Savr tomato. From February 1996 on, the GM puree destined for human consumption was sold in the United Kingdom (UK) (Tencalla, 2006). The last can of GM tomato paste was sold in June 1999 when the retailer excluded GM ingredients from all its own-brand products (Levidow and Bijman, 2002). With the approval of the transgenic soybean event GTS403-2 in April 1996, the door was opened for using imported GM crops as food and feed products over the entire EU. Other approvals soon followed: in January 1997, for instance, the transgenic maize event Bt176 was approved for all commercial uses. According to both market consents (96/281 for GTS40-3-2 soybean and 97/98 for Bt176 maize) no safety reasons required mentioning that the products had been obtained by genetic modification.

Although market consents were previously granted for the cultivation of transgenic crops, their cultivation only started in 1998, after the registration of hybrids derived from Bt176 in the French and Spanish seed catalogues. In 1999, it was the turn for transgenic maize MON810 varieties. These events indicate that GM crops destined for various uses gradually penetrated the European market in the mid-nineties (Tab. 1).

\section{Regulation $258 / 97$ on novel foods and novel food ingredients}

Directive 90/220 covered the deliberate release of GMOs only in generic terms. However, since 15 May 1997, Regulation 258/97 - the so-called Novel Food Regulation removed food products containing, consisting of or produced from transgenic crops from the Directive's scope. This Regulation covered the safety assessment, marketing and labeling of a broad category of novel foods including those produced by new technologies such as genetic engineering, as well as food without a history of safe use in the EU. Recommendation 97/618 provided the scientific basis and information needed to compile dossiers for the marketing of GM food.

Under the Novel Food Regulation, the safety assessment of GM food was based on the principle of substantial equivalence between the GM foodstuff and its non-GM conventional counterpart. The conventional counterparts were generally taken to have a history of safe use, allowing them to serve as baseline in the comparison of their chemical composition and phenotypic characteristics to those of GM foodstuffs (Kok and Kuiper, 2003; König et al., 2004; Levidow et al., 2007; Millstone et al., 1999; Schenkelaars, 2002). 
Y. Devos et al.

Table 1. Overview of commercially authorized GM crop events in the EU per commercial application (pursuant to Directives: $90 / 220$ and 2001/18, and to Regulations: 258/97 and 1829/2003) (Adapted from the Belgian Biosafety Server, http://www.biosafety.be; European Commission, http://ec.europa.eu/food/food/biotechnology/authorisation/index_en.htm) (January 2007).

\begin{tabular}{|c|c|c|c|c|c|}
\hline Commercial application & Crop & Transgenic event & Main trait & Authorization date & Notifier \\
\hline \multirow[t]{6}{*}{ Cultivation } & Chicory & RM3-3, RM3-4, RM3-6 & $\mathrm{HR}, \mathrm{MS}$ & 20/05/1996 & Bejo-Zaden \\
\hline & Maize & $\mathrm{Bt}_{176^{1}}$ & HR, IR & $23 / 01 / 1997$ & Ciba-Geigy \\
\hline & & $\mathrm{T} 25^{1}$ & HR & 22/04/1998 & AgrEvo \\
\hline & & MON810 1,2 & IR & 22/04/1998 & Monsanto \\
\hline & Oilseed rape & MS1 $\times$ RF1 & $\mathrm{HR}, \mathrm{HS}$ & 06/02/1996 & Plant Genetic Systems \\
\hline & Tobacco & ITB1000OX & HR & 08/06/1994 & Seita \\
\hline \multirow[t]{7}{*}{$\overline{\text { Food (all products) }}$} & Maize & Bt176 & HR, IR & 23/01/1997 & Ciba-Geigy \\
\hline & & Bt11 & HR, IR & $19 / 05 / 2004$ & Syngenta \\
\hline & & NK603 & HR & 26/10/2004 & Monsanto \\
\hline & & GA21 & HR & $13 / 01 / 2006$ & Monsanto \\
\hline & & MON863 & IR & $13 / 01 / 2006$ & Monsanto \\
\hline & & 1507 & HR, IR & 03/03/2006 & $\begin{array}{c}\text { Pioneer Hi-Bred International, } \\
\text { Mycogen Seeds }\end{array}$ \\
\hline & Soybean & GTS40-3-2 & $\mathrm{HR}$ & 03/04/1996 & Monsanto \\
\hline \multirow{13}{*}{$\begin{array}{l}\text { Food (only crop } \\
\text { derivatives and products } \\
\text { made with crop } \\
\text { derivatives } e . g \text {. oil) }\end{array}$} & Maize & MON810 & IR & $06 / 02 / 1998$ & Monsanto \\
\hline & & $\mathrm{T} 25$ & HR & 06/02/1998 & AgrEvo \\
\hline & & Bt11 & HR, IR & 06/02/1998 & Novartis \\
\hline & & MON809 & HR, IR & 23/10/1998 & Pioneer \\
\hline & Oilseed rape & Topas19/2 & HR & $24 / 06 / 1997$ & AgrEvo \\
\hline & & MS1 1 RF1 & HR, HS & 24/06/1997 & Plant Genetic Systems \\
\hline & & MS1 $\times$ RF2 & $\mathrm{HR}, \mathrm{HS}$ & 24/06/1997 & Plant Genetic Systems \\
\hline & & GT73 & HR & 21/11/1997 & Monsanto \\
\hline & & Falcon GS40/90 & HR & 08/11/1999 & Hoechst Schering, AgrEvo \\
\hline & & Liberator L62 & HR & 08/11/1999 & Hoechst Schering, AgrEvo \\
\hline & & MS8 $\times$ RF3 & HR, HS & $24 / 04 / 2000$ & Plant Genetic Systems \\
\hline & Cotton & RRC1445 & HR & $19 / 12 / 2002$ & Monsanto \\
\hline & & IPC531 & IR & $19 / 12 / 2002$ & Monsanto \\
\hline \multirow{11}{*}{$\begin{array}{l}\text { Feed, import, } \\
\text { industrial processing }\end{array}$} & Maize & Bt176 & HR, IR & $23 / 01 / 1997$ & Ciba-Geigy \\
\hline & & $\mathrm{T} 25$ & HR & 22/04/1998 & AgrEvo \\
\hline & & Bt11 & HR, IR & 22/04/1998 & Novartis Seeds \\
\hline & & MON810 & IR & 22/04/1998 & Monsanto \\
\hline & & NK603 & HR & $19 / 07 / 2004$ & Monsanto \\
\hline & & MON863 & IR & 08/08/2005 & Monsanto \\
\hline & & 1507 & HR, IR & 03/11/2005 & $\begin{array}{c}\text { Pioneer Hi-Bred International, } \\
\text { Mycogen Seeds }\end{array}$ \\
\hline & & MON863 × MON810* & IR & $16 / 01 / 2006$ & Monsanto \\
\hline & Soybean & GTS40-3-2 & HR & $03 / 04 / 1996$ & Monsanto \\
\hline & Oilseed rape & Topas19/2 & $\begin{array}{l}\mathrm{HR} \\
\end{array}$ & $22 / 04 / 1998$ & AgrEvo \\
\hline & & GT73 & HR & $31 / 08 / 2005$ & Monsanto \\
\hline
\end{tabular}

Abbreviations: $\mathrm{HR}=$ herbicide resistance; $\mathrm{HS}$ = hybrid system; IR = insect resistance; $\mathrm{MS}=$ male sterility.

${ }^{1}$ Genetically modified varieties derived from a transgenic event included in (a) national catalogue(s) of varieties of agricultural plant species (France: 9 Bt176 and 6 MON810 hybrids, Germany: 5 MON810 hybrids; Spain: 36 MON810 hybrids; the Netherlands: 1 T25 hybrid).

${ }^{2}$ Genetically modified varieties derived from a transgenic event included in the common EU catalogue of varieties of agricultural plant species (31 MON810 varieties).

* Except for feed uses. 
Nonetheless, that conventional food products are generally safe is merely an assumption. Indeed, very few of them have been subjected to toxicological studies. Also, the degree of difference necessary to determine when the substance of the GM foodstuff ceases to be acceptably equivalent to the conventional counterpart was not defined clearly. Because of this, the substantial equivalence principle remained open to a diversity of interpretations, making its implementation in practice rather complicated and contentious. Other critical points were uncovered. First, substantial equivalence was often misperceived as the endpoint of a safety assessment, rather than the starting point. Initially, no risk assessment was required when a GM food was substantially equivalent. Second, it appeared to be difficult to predict the biochemical or toxicological effects of a GM food from its chemical composition. Third, complaints were made that it was not an absolute safety assessment in itself: not all the potentially harmful components are assessed, since some of these components may not be associated with the genetic modification. Fourth, a comparative safety assessment could not be done if no appropriate comparator is identified, requiring a comprehensive safety and nutritional assessment of the GM foodstuff per se.

Following the growing criticism of substantial equivalence as a basis to evaluate GM food, the principle was interpreted more strictly over time. Only products without detectable traces of the new DNA or protein could be notified under the simplified procedure, whereas products not satisfying these criteria underwent a full risk assessment under the normal authorization procedure.

With the Novel Food Regulation, foodstuffs were subjected to specific labeling requirements, thereby complementing Directive 97/4 on the labeling, presentation and advertising of foodstuffs. The consumers' right to be informed of any characteristic or food property was extended to novel food or food ingredients that differed materially from existing ones, hence allowing consumers to make an informed choice on the basis of their own values. The modified characteristics and the method used thus had to be mentioned on the label. Labeling was also required when (1) the novel food contains material that is not present in an existing equivalent foodstuff, and which may have implications for the health of certain sections of the population; and when (2) the presence of such material gives rise to ethical concerns (Christoforou, 2004). Although the precise meaning of these ethical concerns was not clarified, they were received in terms of people perceiving GM agro-food products as "unnatural", as "a violation of the sanctity of species", as "disrespectful for nature", or as "incompatible with organic farming" (Streiffer and Hedemann, 2005; Streiffer and Rubel, 2004).
According to the labeling provisions of the Novel Food Regulation, labeling was not required when a genetically engineered raw material had been treated technically in such a way that neither the new DNA nor the protein could be detected in the final product. Since May 1997, processed oil from GM oilseed rape, maize and cotton, and processed food and food ingredients derived from GM maize have been notified as being substantially equivalent and thus approved for human consumption under the simplified procedure of the Novel Food Regulation. Moreover, labeling did not apply to foodstuffs already used for human consumption in the EU prior to the establishment of the Novel Food Regulation. Already marketed foodstuffs, such as GTS40-3-2 and Bt176, were not considered as novel. Nor did the EC see reasons to label these products judged to be safe as being obtained by genetic modification. However, with the adoption of Regulations $1813 / 97$ and $1139 / 98$, the labeling of GTS40-3-2 and Bt176 foodstuffs also became compulsory. From that moment on, the label literally had to contain the words 'produced from GM soybean' or 'produced from GM maize' when the new protein or transgene were detectable in the end product intended for consumption. With Regulation 50/2000, the labeling provisions were extended to additives and flavorings that have been genetically modified or that have been produced from a GMO.

\section{DE FACTO MORATORIUM ON THE COMMERCIALIZATION OF NEW GM CROP EVENTS}

GM crops were initially restricted to and confined in research and development laboratories. However, they soon gained presence in agricultural fields, in the supply chains and - to a lesser extent - on supermarkets' shelves and on consumers' plates. They directly and physically entered the public sphere, which largely amplified the opposition to GM crops in the EU.

The growing opposition was played out in various arenas (Bonneuil et al., in press; Gruère, 2006; Kalaitzandonakes and Bijman, 2003; Lassen et al., 2002; Levidow and Bijman, 2002; Levidow et al., 2005). In 1996, non-governmental organizations (NGOs) blockaded shipments containing GM soybean or maize, because the providers decided not to segregate GM and nonGM agro-food products. Under the influence of intensive NGO campaigns, consumers boycotted GM agro-food products. Major supermarket chains excluded GM ingredients from their own-brand food products, as a measure to respect consumers' preferences. The food industry adopted negative labeling to guarantee the absence of GM material in foodstuffs, and the retail food chains 
launched bans against products from animals reared on feed produced from GM crops. Portugal withdrew the two inscribed GM maize hybrids from its seed catalogue, prohibiting their further cultivation on the Portuguese territory.

The assessment of market notifications led to serious regulatory-expert disputes between European and national safety assessment bodies. Conflicting positions were at play concerning the kinds of risk to assess or to ignore, the reliability of scientific evidence, the baseline of comparison to use for assessing the severity and acceptability of risk, and about the means of managing uncertain risks (Carr, 2002). Value judgments, which are required to characterize risks and to determine the acceptability of health and environmental impacts, differed among EU institutions and MS. At the EU level, these issues were treated generally as technical ones, thereby downplaying long-term adverse effects and socio-cultural values underlying science, whereas some MS applied relatively broader precautionary accounts by defining risk in broader ways (Levidow, 2001). Consequently, some MS invoked national safeguard clauses to provisionally restrict or prohibit the use and/or sale of authorized GM agro-food products on their territory. In August 2000, for instance, the Italian government suspended the sale of products derived from four GM maize events, approved under the simplified procedure of the Novel Food Regulation. The government's opinion was that substantial equivalence had not been properly shown, requesting a full risk assessment (Levidow et al., 2007). Like some MS, various NGOs defined risk broadly, linking it frequently to a sustainability discourse.

Some scientists, regulators and NGOs started to question the appropriateness of small-scale, short-term and strictly confined field trials in forecasting the risks under real agricultural situations over a longer time frame (Firbank et al., 2005), as well as the domination of biotechnologists in regulatory and expert arenas (Bonneuil et al., in press).

At the June 1999 meeting of the Environmental Council, Austria, Denmark, France, Greece, Italy and Luxembourg decided not to accept new market consents of new GM crop events as long as the existing regulatory frame was not revised. This de facto moratorium hindered the commercialization of GM agro-food products in the EU. First, stronger legislations were requested, with more stringent, transparent and precautionary risk assessment criteria, in order to improve the safety assessment of GM agro-food products. Legal clarifications were also requested on environmental liability, in case of environmental damage caused by the deliberate release of GM crops. These societal demands focused on the availability of safe GM agro-food products to consumers, and the protection and maintenance of the environment and its biodiversity. Second, the implementation of labeling, traceability, co-existence and public registers was requested to respect the consumers' and farmers' freedom of choice, and to provide information about GM agro-food products to the public (Brom, 2000; Mepham, 2000; Nielsen and Faber, 2002; Paula and van den Belt, in press).

The complicated legal situation, combined with the negative public perception of GM crops and the systematic destruction of field trials by activists, resulted in the cutting-down and/or holding-off of research activities in plant biotechnology. Despite favorable risk assessments, the acquisition of a permit for field trials was no longer obvious. As a result, the number of field trials - being the intermediate step when applying for market consent - showed a drastic drop of $76 \%$ between 1998 and 2001 (Lheureux and Menrad, 2004). Notifiers lost their confidence in existing authorization processes, and many research and development departments were relocated to other world areas (Mitchell, 2003; Tencalla, 2006).

From this period on, public attention to the potential adverse impact of GM crops was nourished by various events: statements of opposition from the UK's Prince Charles, the scientist Pusztai announcing on the British television that rats fed with GM potato - modified to express snowdrop bulb lectin - suffered adverse health effects, the findings of Losey and colleagues who reported that monarch butterfly larvae were susceptible to harm from Bacillus thuringiensis $(B t)$ toxins when fed with pollen of $B t$ maize, the various actions of the organized network of trolley watchers directed towards GM foodstuffs and supermarkets selling these products, and the increasing media coverage reflecting the bold rhetorical and metaphorical discourses of both GMO opponents and proponents (Cook et al., 2006; Petersen, 2005). A series of scandals on food safety amplified the suspicion of the public towards policy makers, industry and scientists, and extended national regulatory differences. Broader ethical and socio-economical concerns entered the GM debate where risk concerns occupied a prominent position, especially in France, under the influence of the anti-globalization leaders (Heller, 2002; Marris et al., 2005). Questions relating to, e.g., the agronomic and socio-economic relevance of transgenic crops, their usefulness and sustainability, the type of food and agriculture wanted, the standardization of food, the independence of public research became more prominent. Later, the GM controversy also moved to local scenes, with local authorities and regional governments voting bans on the cultivation of transgenic crops on their territory. Actors that had a muted voice in the GMO debate, succeeded in forging coalitions, leading to the creation of an impressive number of GM-crop-free zones all over the EU. This movement emphasized a request of many regional and local 
Table 2. Historical overview and scope of the European regulatory frame coping with GM crops from 1990 onwards (using the adoption dates of legal texts).

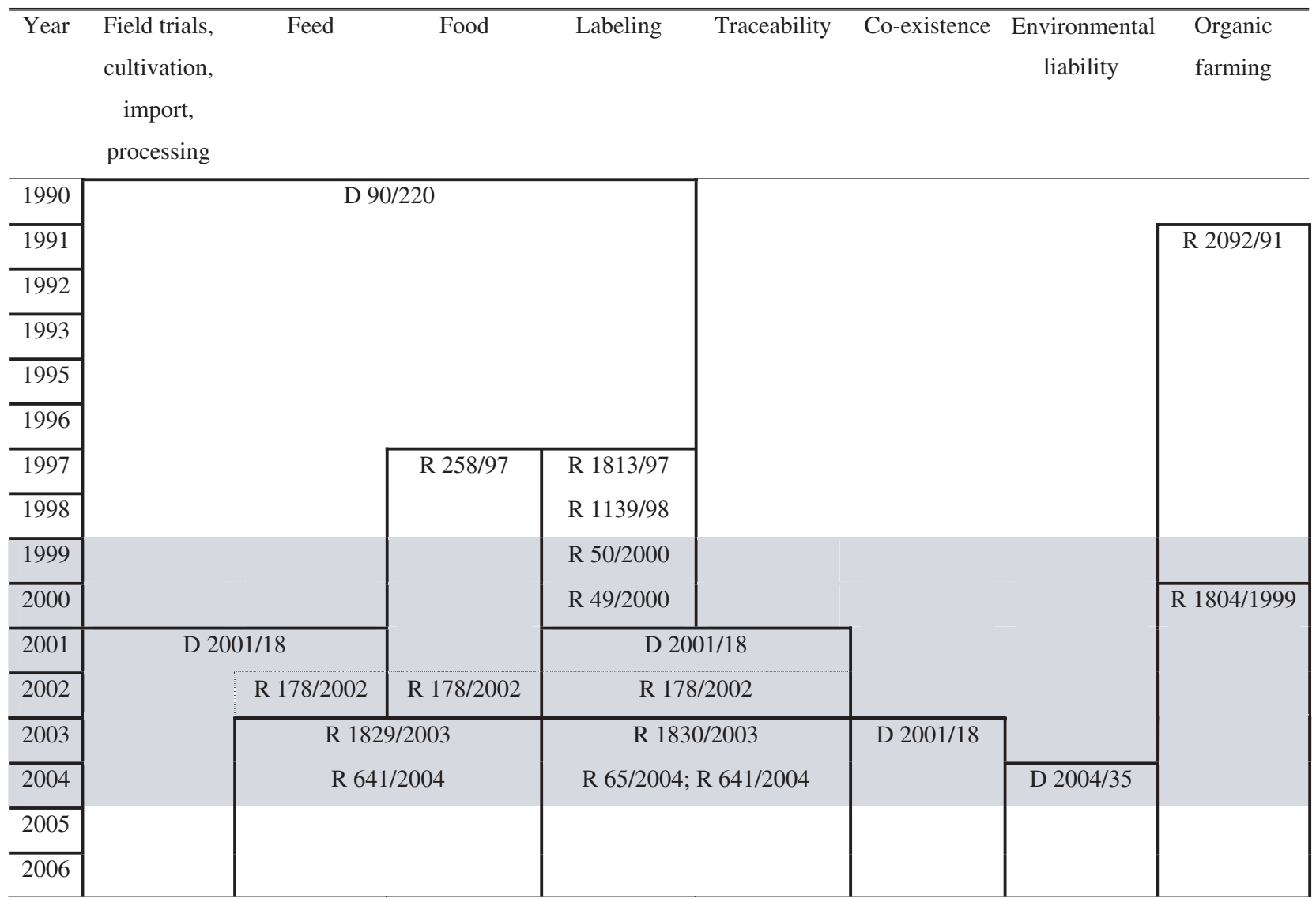

Abbreviations: $\mathrm{D}=$ Directive; $\mathrm{R}=$ Regulation.

Grey zone: de facto moratorium on the commercialization of new GM crop events.

authorities to decide whether GM crops can be cultivated on their territory. With these evolutions, the inadvertent mixing of GM and non-GM agro-food products and the co-existence between cropping systems emerged as additional issues in the GMO debate (Levidow and Boschert, in press).

\section{RESTYLING OF THE EUROPEAN REGULATORY FRAME ON GM CROPS}

During the de facto moratorium various waves of institutional reform led to a gradual revision of the existing legislations and to the creation of new EU institutes. Both general and product-specific legislations were introduced in order to replace or amend older ones. Through this, specific values, norms, criteria and principles already present in the regulatory frame were strengthened and harmonized, whilst new ones were implemented. These regulatory revisions are discussed below in more detail in order to pinpoint the accompanying change in values (Tab. 2).

\section{Restyling I: Directive 2001/18: a new view on the deliberate release into the environment of genetically modified organisms}

On 17 October 2002, after years of preparation and discussion within the European Council and European Parliament, Directive 2001/18 replaced the older Directive 90/220. This Directive took into account the latest scientific research and international legal developments (Christoforou, 2004). With it, the precautionary principle was explicitly adopted as a guide, the risk assessment criteria were broadened to include direct, indirect, immediate, delayed and cumulative long-term adverse effects, post-market monitoring became obligatory, the need for a 
Y. Devos et al.

common methodology for the environmental risk assessment was established, the phasing out of certain antibiotic resistance marker genes was introduced, the existing labeling provisions applying to GM foodstuffs were extended to all the marketed products containing GMOs, the general concept of traceability at all stages of commercialization was introduced, the transparency in the decision-making process was increased, the consultation of the public became mandatory in the authorization procedure, the possible consultation of an ethics committee was confirmed, and the implementation of national cultivation registers that record the locations where GM crops have been cultivated was required. In the remainder of this chapter, several of these themes are discussed in more detail, starting with the precautionary principle.

\section{Explicit adoption of the precautionary principle $(P P)$ in the new Directive}

Compared to its predecessor, a major shift in Directive 2001/18 is the explicit adoption of the PP as a guide. The Directive states that (1) "the PP has been taken into account in the drafting of the Directive and must be taken into account when implementing it"; and that (2) "MS shall, in accordance with the PP, ensure that all appropriate measures are taken to avoid adverse effects on human health and the environment, which might arise from the deliberate release or the placing on the market of GMOs". With its increasing acceptance as a general principle in (inter)national law, various interpretations have been given to the PP; some authors have even defined the $\mathrm{PP}$ as an ethical principle that risk assessors and risk managers should adopt in the face of scientific uncertainty (Carr, 2002; Jensen, 2002). Based on a number of different versions of the PP, Sandin (1999) extracted four common dimensions of the PP and expressed them in the following if-clause: "if there is (i) a threat, which is (ii) uncertain, then (iii) some kind of action (iv) is mandatory". In this if-clause, the threat dimension concerns possible damages or harm of an activity, which can be qualified as serious, significant or irreversible. The uncertainty dimension expresses the need for scientific uncertainty to take precautionary measures, and thus relates to the limits of scientific knowledge on suspected risks. While the action dimension rather concerns possible responses to the uncertain threat, the final command dimension focuses on the way in which action is prescribed (Sandin, 1999).

In the following section we will address how these dimensions are reflected in the legal criteria created by Directive 2001/18 and in the "Communication on the PP" issued by the EC (CEC, 2000), and how these dimensions are translated in practice.

(i) Threat dimension: In Directive 2001/18, qualifying adjectives referring to risks are only used in the preamble and the guidance note that supplements Annex II. In a risk analysis done in accordance with the provisions of Directive 2001/18, judgments are made about what counts as a harmful impact. When an effect is defined as adverse or harmful it implies that the deterioration in quality of a particular environmental subject exceeds a certain chosen level of environmental protection (CEC, 2000). Directive $2004 / 35$ on environmental liability here defines environmental damage as "a measurable change in a natural resource or measurable impairment of a natural resource service, which may occur directly or indirectly". It is the severity of a potential adverse effect combined with the level of scientific uncertainty that triggers precaution.

In risk analysis, one thus first has to define the environmental subjects considered relevant to assess/protect or considered valuable for society. The conservation objectives set by Directive 2001/18 are of a general nature, aiming at a high level of protection of human health and the environment. Despite this general nature, the previous environmental risk window is broadened, by requiring the assessment of potential direct, indirect, immediate, delayed and cumulative long-term adverse effects. Consequently, more agro-ecological expertise is included, and a set of new subjects implicitly enters the scope of the environmental risk assessment. Previously, for instance, indirect adverse effects on farmland biodiversity caused by the use of non-selective herbicides on GM crops fell beyond the remit of Directive 90/220, because they were considered to be agronomic issues. However, MS that prioritized the protection of farmland biodiversity or that aimed at reducing agro-chemical usage to ensure the use of ground water as drinking water already included this issue in their assessments (Levidow, 2001). Nowadays, it is considered to be a statutory criterion (ACRE, 2004a, 2005; BAC, 2004).

After identifying the deterioration in quality of a particular subject, one has to define whether it exceeds a certain chosen level of environmental protection (CEC, 2000). The baseline against which this change is compared allows determining its severity and acceptability. According to EC standards, the most dominant form of agriculture is considered as the baseline for comparison. It means that an adverse effect due to the use of a transgenic crop is acceptable as long as the effect remains within the range of variability observed in conventional agriculture.

Although such a comparative approach - relying on the concept of familiarity - is a useful tool in the risk analysis of GM crops, it does show some weaknesses, due to a rather uncritical conception of conventional farming. Despite the general assumption that conventional farming is safe, it is known that biodiversity associated with many conventional crops is declining due to, for instance, the increased use of fertilizers and pesticides and/or the 
Societal concerns and EU regulatory frame on GM crops

shift from spring to winter cropping (Chamberlain et al., 2000; Robinson and Sutherland, 2002). Also the Farm Scale Evaluations have shown that differences in the impact on wild flora and fauna can be greater between different conventional crops (e.g. between maize and oilseed rape) than between a GM herbicide resistant crops and its non-GM herbicide susceptible counterpart (Firbank et al., 2005). In this context, a comparative approach is still flawed because it may permit the use of a harmful GM crop on grounds that the comparator also causes harm. It may also be the case that less harm is tolerated for GM crops, whereas conventional practices are equally or more harmful. For example, although a conventionally bred herbicide resistant crop could generate similar impacts as the GM one, it is unlikely that it would be assessed (ACRE, 2006; Chassy et al., 2003).

Another difficulty is translating statistical significant adverse effects into significant biological or ecological effects: a reduction in soil biodiversity does not necessarily cause a decrease in soil function (Lilley et al., 2006).

Also, the assessment of the wider impact of GM crops and their associated agricultural practices is not promoted. This is because a harm-oriented approach is followed rather than a goal-oriented one (Deblonde and du Jardin, 2005). As such, single GM crops are assessed, but not the whole agricultural system. Within a wider assessment frame, a potential risk may be traded against potential benefits. However, Directive 2001/18 currently does not permit a GMO to progress to a sustainability assessment if a single biologically significant harmful environmental effect is detected, irrespective of any potential environmental benefits that it could offer (ACRE, 2006).

Finally, it has been argued that judgments about the acceptability of impacts should not only be based on conventional farming, but also on organic or integrated farming in order to strike a new balance between agricultural production and biodiversity. In Austria, Germany and Italy, for instance, GM agro-food products are considered to constitute a threat to organic or integrated agriculture or to local traditional products, and thus to national values (Levidow, 2001). However, also this option is not easy to implement: applying different baselines among European institutions and MS has already led to contentious positions on the acceptability of risks. This illustrates that various accounts of precaution are identifiable at the EU level (Levidow et al., 2005). Depending on the accounts taken, some MS not only consider dangerous effects, but also encompass undesirable ones in risk assessments.

(ii) Uncertainty dimension: According to the EC, "the absence of proof of the existence of a cause-effect relationship", "a quantifiable dose/response relationship" or "a quantitative evaluation of the probability of the emergence of adverse effects following exposure" can trigger precautionary measures (CEC, 2000). Depending on the precautionary accounts taken, EU practice shows that precautionary measures were taken not only when the scientific plausibility of the suspected risk is to some extent verifiable, but also when there were suspicions or inadequate evidence about uncertain risks (Levidow et al., 2005).

Through the adoption of the PP in Directive 2001/18, it is recognized that risk assessments are limited by a degree of scientific uncertainty, ignorance, indeterminacy, ambiguity and inconclusiveness, and that decisions must be made acknowledging that these shortcomings may not be resolved (Carr, 2002; CEC, 2000; Hoffmann-Riem and Wynne, 2002; Krayer von Krauss et al., 2004; Sanvido et al., 2005; Wandall, 2004). This is also the tenor of the EC guidance note for the environmental risk assessment (2002/623) that supplements Annex II of Directive 2001/18: it recommends "describing uncertainties, clarifying the assumptions, extrapolations and predictions made, explaining the differing points of view, and discussing the known limits". In this respect, there is an attempt to render explicit the value judgments and pluralistic viewpoints occurring in, as well as the limitations of risk assessment. These clarifications are intended to allow risk managers to judge whether the factual basis of the risk assessment is sufficiently reliable to act upon. So far, these clarifications have in fact remained implicit at the EU level. Levidow and Carr (in press) observed that the scientific opinions of the European Food Safety Authority (EFSA) "generally have framed scientific uncertainties in such a way that they can be resolved by extra information, or can be readily managed, or can be deemed irrelevant to any risk". Moreover, the EFSA harmonized expertise to provide consensual objective opinions, downplaying diverse views and limitations (Levidow and Carr, in press). This trend may be explained by the fact that risk managers may no longer receive opinions that are straightforward, and that expert disagreement about the reliability of scientific evidence for risk assessments may reduce public credence in science-based policy.

(iii) Action dimension: The idea of responding to an uncertain threat is generally translated in terms of bringing restrictions to the free movement of GM agro-food products, provided that these are "proportional to the desired level of protection", "non-discriminatory in their application", "consistent with measures already adopted in similar circumstances", "consider the costs and benefits of both action and lack of action", and "consider developments in scientific knowledge" (CEC, 2000). The heated debates about the potential occurrence of feral oilseed rape populations along transportation routes due to grain spillage - induced by the assessment of the notification that covered the import of the oilseed rape GT73 event illustrated divergent positions on how to manage uncertain risks. The potential occurrence of feral oilseed rape 


\section{Y. Devos et al.}

populations was judged as unacceptable by some MS, demanding specific controls to prevent spillage and requiring its monitoring, whilst others and the EFSA found no grounds for any risk (Levidow, 2006).

Under Directive 2001/18, mandatory environmental post-market monitoring (PMM) has been chosen as the privileged precautionary measure to cope with scientific uncertainties. Generally, monitoring relies on checking if certain standards are met, examining potential changes with respect to an established baseline, and/or reducing the scientific uncertainties that were identified in risk assessment. Since not all potential scientific uncertainties can be assessed prior to release, PMM is relevant, although further research may not always overcome these uncertainties.

Annex VII of Directive 2001/18 and its supplementing guidance note (2002/811) describe an environmental monitoring plan consisting of case-specific monitoring and general surveillance: general surveillance is always obligatory, whilst case-specific monitoring is imposed on a case-by-case basis (EFSA, 2006a). Due to the different objectives between case-specific monitoring and general surveillance, their underlying concepts differ (ACRE, 2004b; EFSA, 2006a; Sanvido et al., 2005). In the former, foreseen potentially adverse changes are related to specific causes (known unknowns), whereas in the latter the detection of unforeseen changes without known specific cause (unknown unknowns) is aimed at. Casespecific monitoring is mainly triggered by scientific uncertainties that were identified in risk assessment. Hence, a hypothesis is established that can be tested on the basis of the newly collected data. In contrast, in general surveillance, the general status of the environment that is associated with the uses of GM crops is monitored without any preconception. Here, effects - including cumulative long-term effects - that were not anticipated in the environmental risk assessment are sought. Then, it has to be determined whether the unusual effect detected is adverse, and whether it is associated with the use of a transgenic crop.

In the elaboration of its guidance note on environmental PMM, the EFSA consulted a wide range of actors (EFSA, 2006a). From these discussions, it arose that the approaches and principles of environmental PMM are diversely interpreted, reflecting different precautionary accounts. According to narrow accounts, PMM is only justified until additional scientific evidence is obtained that allows a more complete risk assessment. This offers the possibility to define whether the risk assessment has changed or whether risk management should be changed. Within broader precautionary accounts, research is not only needed to fill data gaps, but also to improve the bases of available knowledge. On the basis of Annex VII of Directive 2001/18, some plead that monitoring should be done to confirm the correctness of any assumption on the occurrence and impact of potential adverse effects of the GMO or its use made in the environmental risk assessment. However, the EFSA emphasized that this goes far beyond the remit of the PP, since monitoring plans would not only cover the 'known unknowns', but also the 'known knowns'. PMM aims at elucidating the 'known unknowns' related to potentially harmful risks in order to confirm or refute uncertain assumptions made in the environmental risk assessment, whereas an adverse 'known known' can be managed preventively to reduce the anticipated risk to an acceptable level. The 'nice to know' versus 'need to know' divergences are also reflected in the demands to apply an unconditionally surveillance of all areas exposed to GM crops or likely to be affected by their cultivation, to conduct intensive biosafety programs, to require a null hypothesis in general surveillance, and/or to establish comprehensive lists of protection goals (EFSA, 2006a).

Where any environmental damage was observed, the output of PMM could be coupled to environmental liability, in order to trigger remedial measures and liability. However, Karlsson (2006) doubts that "environmental liability will have any meaning when it comes to the ordinary use of GM crops, since the environmental liability Directive gives exceptions for authorized activities".

(iv) Command dimension: Directive 2001/18 mentions that "MS shall, in accordance with the PP, ensure that all appropriate measures are taken to avoid adverse effects on human health and the environment, which might arise from the deliberate release or the placing on the market of GMOs".

As mentioned above, the PP has been explicitly adopted in the new Directive 2001/18. Nonetheless, before, an implicit precautionary approach was already applied. This can be demonstrated through different aspects of the older regulatory frame.

For example, the iterative process of risk analysis always has been precautionary in the sense that its decisions are temporary, reversible and adaptable in the light of new information that becomes available. With the advent of new information, it had to be defined whether the risk assessment has changed, or whether risk management should be changed. Under Directive 2001/18, this duty of re-examination has been strengthened by limiting the duration of market consent to a maximum of ten years.

A precautionary approach also was reflected in the right of a MS to provisionally restrict or prohibit the use and/or sale on its territory of an approved GMO. Even more, some MS already applied the PP by enforcing monitoring activities in the face of scientific uncertainties. In France, for instance, research on vertical gene flow and its agro-ecological consequences was funded (Marris et al., 


\section{Societal concerns and EU regulatory frame on GM crops}

2005), whereas in the UK, harm to farmland biodiversity caused by herbicide use was assessed in the Farm Scale Evaluations (Oreszczyn, 2005).

Finally, entire categories of products for which there was no prior evidence of harm were a priori regulated, to guarantee the protection of human health and the environment, and to predict and avoid harm (Levidow, 2001). The burden of proof to demonstrate biosafety prior to use was in the hands of those who claim that the activity in question causes no adverse effects. Notifiers are in charge of providing a risk assessment, which is generally done (1) in accordance to the latest standards of scientific knowledge; (2) on a case-by-case basis, because few generic judgments can be made about the safety and impact of GM crops; and (3) step-wise - according to a tiered approach - where the assessment increases in complexity and realism based on the knowledge gained during previous steps. Subsequently, MS evaluate the scientific quality of the submitted notifications, request additional information, take steps to ensure that human health and the environment are protected, and guarantee that the risks associated with the use of an authorized GMO are considered to be very low. In this process, some MS requested more reliable or complete information, and/or challenged the available evidence, especially on molecular characterization or toxicological tests (Levidow et al., 2005).

The overall precautionary character of the EU legislation on GM crops - in both its implicit and explicit form - has been doubted, because "ignorance and uncertainty are poorly dealt with, complex social and political judgments are made by experts in ways that are not transparent, and there is little opportunity for public participation" (Karlsson, 2006; Mayer and Stirling, 2002). Moreover, some prescribe an interpretation of precaution that is explicitly linked to the ideal of sustainable development (ACRE, 2006; Deblonde and du Jardin, 2005).

\section{A common methodology for environmental risk assessment (ERA)}

The objectives of the ERA are to identify adverse effects of GMOs and to measure and predict their seriousness, as well as their likelihood of occurrence. Before the new Directive, ERA frameworks varied considerably in the number and definition of particular action steps and in the terminology used to describe these steps. Experts from different disciplines understood the conceptual basis for risk assessment differently or confused the successive steps (Hill, 2005; Hill and Sendashonga, 2003). For instance, when transgene flow towards certain wild/weedy relatives is considered as a problem in itself, the risk assessment will be limited to the exposure step in order to estimate vertical gene flow. However, the estimation of vertical gene flow per se is not generally considered to be a complete risk assessment: it requires not only an evaluation of exposure, but also the evaluation of the potential adverse consequence(s) resulting from vertical gene flow (Chapman and Burke, 2006; Hails and Morley, 2005).

To avoid further confusion and to promote a common understanding of the ERA, the guidance note (2002/623) that supplements Annex II of the new Directive describes a common conceptual basis and methodology for the ERA. An ERA now consists of six successive steps: (1) characteristics which may cause adverse effects are identified; (2) potential consequences of each separate adverse effect are estimated and evaluated; (3) likelihood of occurrence of each identified potential adverse effect is evaluated; (4) risk posed by each identified characteristic of the GMO is estimated; (5) management strategies are chosen and applied; and finally; and (6) overall risk of the GMO is determined.

Despite this conceptual and methodological harmonization, the practical definition of adverse effects, which proved to be contentious at EU level, remained unaddressed.

\section{Phasing out of antibiotic resistance marker (ARM) genes}

In the transformation process of GM crops, ARM genes are commonly used to enable the selection of transformed plant cells and/or of the vector constructs used. With the cumulative and large-scale release of different GM crop events containing ARM genes, an unwanted increase in existing levels of antibiotic resistance in microorganisms was feared, due to its possibility to compromise therapy. However, risk assessments have generally concluded that (1) the frequency of horizontal gene transfer from GM crops containing ARM genes towards microbial populations is very low; (2) the hazard arising from any such gene transfer is, at worst, slight; but that (3) their use should be strongly discouraged when they could compromise the use of clinically relevant antibiotics (Bennett et al., 2004; EFSA, 2004a; Goldstein et al., 2005; van den Eede et al., 2004).

Following this line of arguments, and in accordance with the PP, Directive 2001/18 requires the phasing out of genes encoding resistance to antibiotics in use for medical or veterinary treatment by 2005 for commercial releases, and by 2009 for research purposes, provided that the genes have adverse effects on human health and the environment. NGOs and some MS welcomed this turn in regulatory policy on ARM genes; they judged the possibility of ARM gene transfer as unacceptable. Relying on broader precautionary accounts, they requested the complete elimination of ARM genes. On these grounds, many notifications for field trials were rejected in the EU. 


\section{Y. Devos et al.}

Following the various objections raised by MS regarding the presence of ARM genes in notified GM agrofood products, the EFSA was consulted to provide clear guidance. Considering their clinical importance and the availability of alternatives, ARM genes were categorized into three groups by the EFSA. The first group contained ARM genes that are already widely distributed in microorganisms in the environment, and which confer resistance to antibiotics of minor or no clinical relevance, such as $n p t I I$, which confers kanamycin resistance. Since there is no rationale for inhibiting or restricting the use of these ARM genes, the EFSA judged their use in GM plants as permissible. The ARM genes contained in the other two groups conferred resistance to antibiotics that are clinically relevant or highly relevant (e.g. streptomycin, tetracycline). Their use in GM plants destined for experimental or commercial release should be restricted or prohibited (EFSA, 2004a).

Following the EFSA opinion, Spain recently withdrew the five inscribed Bt176 hybrids from its seed catalogue: the ARM gene present in Bt176 - ampicillin resistance - belongs to the group of ARM genes whose use had to be restricted to field trials. The French seed catalogue still counts nine Bt176 hybrids, but these have not been cultivated commercially since 1999 . The reason is that transgene expression in these hybrids drops after pollination, reducing the protection against the targeted pest insects (Tab. 3). Since the more stringent criteria adopted by some MS were not acknowledged in the EFSA opinion, they maintained their objections to the presence of ARM genes in notified GM agro-food products.

\section{Public consultation and information}

Under Directive 2001/18, the consultation of the public and other actors during the authorization procedure also became mandatory. This is based on the assumption that public consultation enables risk managers to make better informed decisions, since they will better understand divergent interpretations of uncertainties and the underlying values held by different actors (Irwin, 2006; Karlsson, 2003b; Schibeci et al., 2006). For commercial releases, this consultation is organized at the European level, whereas it is organized at the national level for experimental releases. In both cases, the Summary Notification Information Format (SNIF) serves as the main source of information.

Unfortunately, the template and content of the SNIF did not develop along with the changes made in Directive 2001/18. Under the old Directive 90/220, the SNIF was only exchanged between MS as an early warning system to rapidly identify potential adverse risks: MS demanded technical and summarized information. Nowadays, the same SNIF is made available to the public, but it does not address societal concerns.

In response to this weakness, in Belgium, the "public files' were institutionalized. Under guidelines specifically designed for the compilation of public files, notifiers were recommended to address questions about the added value of the envisaged releases and the technology used, about arguments of choice of technology, and about weighing alternatives. Emphasis was put on the semantic accessibility of these public files.

Despite these efforts, and despite the fact that public comment is currently allowed for, only those criteria included within the prescribed risk assessment of the Directive are taken into account in market decisions (Karlsson, 2006; Mayer and Stirling, 2002). Hence, the tendency to overlook societal issues in the authorization procedure seems to continue, giving European public consultation a mere symbolical or ritual character (Irwin, 2006). In case of experimental releases, the situation is somewhat different: MS retain a larger competence and, generally, apply broader precautionary accounts. Some MS used this flexibility to create room to take public comments seriously.

\section{Consultation of an ethics committee}

Another new element in Directive 2001/18 is that the Commission's European Group on Ethics in Science and New Technologies can evaluate ethical issues of a general nature. This Group is an independent, pluralistic and interdisciplinary authority. This possibility offers an 'opening' to address some of the ethical concerns underlying public skepticism towards GM agro-food products. Still, it needs to be said that, by its recommendations the consultation envisaged is not supposed to stop or delay the consent procedure or to change the consent (Jensen et al., 2003; Madsen and Sandøe, 2005). Already in 1995, the Group provided an opinion on the ethical aspects of the labeling of food derived from modern biotechnology. According to this opinion, the primary ethical imperatives applying to marketed GM agro-food products relate to their safety, labeling, benefits and free movement in the EU (EGE, 1995).

Yet, MS retain a competence regarding ethical issues because the Directive states that (1) "respect for ethical principles recognized in a MS is particularly important"; (2) "MS may take ethical aspects into consideration when GMOs are deliberately released or placed on the market as or in products"; and that (3) "MS should be able to consult any committee they have established with a view to obtain advice on the ethical implications of biotechnology". Due to a lack of concrete substantial and/or procedural recommendations, some MS doubt the sincerity of these statements. Other MS explicitly address ethical 
Societal concerns and EU regulatory frame on GM crops

Table 3. Numbers of GM maize varieties registered in or withdrawn from national catalogues and/or common EU catalogue of varieties of agricultural plant species and area cropped with GM maize in the EU (data adapted from personal communications of Bartsch D, Carvalho P, Cerovska M, Fresno Ruiz A, Grevet A, Hervieu F, Köller M, Roda Ghisleri L and Tencalla F, and from the consultation of national and the common EU catalogue(s) up to January 2007).

\begin{tabular}{|c|c|c|c|c|c|c|c|c|c|c|c|c|c|c|c|}
\hline \multirow[t]{3}{*}{ Year } & \multirow[t]{3}{*}{ Event } & \multicolumn{14}{|c|}{ Number of registered $(+)$ or withdrawn $(-)$ varieties (Var) // Area (ha) of GM maize (Acr) } \\
\hline & & \multicolumn{2}{|c|}{$\mathrm{CZ}$} & \multicolumn{2}{|c|}{$\mathrm{DE}$} & \multicolumn{2}{|c|}{ ES } & \multicolumn{2}{|c|}{ FR } & \multicolumn{2}{|c|}{ NL } & \multicolumn{2}{|c|}{ PT } & \multicolumn{2}{|c|}{ EU } \\
\hline & & Var & Acr & Var & Acr & Var & Acr & Var & Acr & Var & Acr & Var & Acr & Var & Acr \\
\hline \multirow[t]{3}{*}{$1997 *$} & Bt176 & 0 & 0 & 0 & 0 & 0 & 0 & 0 & 0 & 0 & 0 & 0 & 0 & 0 & 0 \\
\hline & MON810 & 0 & 0 & 0 & 0 & 0 & 0 & 0 & 0 & 0 & 0 & 0 & 0 & 0 & 0 \\
\hline & Total & 0 & 0 & 0 & 0 & 0 & 0 & 0 & 0 & 0 & 0 & 0 & 0 & 0 & 0 \\
\hline \multirow[t]{3}{*}{$1998 * *$} & Bt176 & 0 & 0 & 0 & 0 & +2 & 22320 & +9 & 1500 & 0 & 0 & 0 & 0 & 0 & 23820 \\
\hline & MON810 & 0 & 0 & 0 & 0 & 0 & 0 & +6 & 0 & 0 & 0 & 0 & 0 & 0 & 0 \\
\hline & Total & 0 & 0 & 0 & 0 & 2 & 22320 & 15 & 1500 & 0 & 0 & 0 & 0 & 0 & 23820 \\
\hline \multirow[t]{3}{*}{1999} & Bt176 & 0 & 0 & 0 & 0 & 0 & 24950 & 0 & 0 & 0 & 0 & +1 & 280 & 0 & 25230 \\
\hline & MON810 & 0 & 0 & 0 & 0 & 0 & 0 & 0 & 150 & 0 & 0 & +1 & 1120 & 0 & 1270 \\
\hline & Total & 0 & 0 & 0 & 0 & 2 & 24950 & 15 & 150 & $+1 * * *$ & 0 & 2 & 1400 & 0 & 26500 \\
\hline \multirow[t]{3}{*}{2000} & Bt176 & 0 & 0 & 0 & $?$ & 0 & 25280 & 0 & 0 & 0 & 0 & -1 & 0 & 0 & 25820 \\
\hline & MON810 & 0 & 0 & 0 & $?$ & 0 & 0 & 0 & 34 & 0 & 0 & -1 & 0 & 0 & 34 \\
\hline & Total & 0 & 0 & 0 & $<100$ & 2 & 25820 & 15 & 34 & 1 & 0 & 0 & 0 & 0 & 25954 \\
\hline \multirow[t]{3}{*}{2001} & Bt176 & 0 & 0 & 0 & $?$ & 0 & 11450 & 0 & 0 & 0 & 0 & 0 & 0 & 0 & 11450 \\
\hline & MON810 & 0 & 0 & 0 & $?$ & 0 & 0 & 0 & 15 & 0 & 0 & 0 & 0 & 0 & 15 \\
\hline & Total & 0 & 0 & 0 & $<100$ & 2 & 11450 & 15 & 15 & 1 & 0 & 0 & 0 & 0 & 11565 \\
\hline \multirow[t]{3}{*}{2002} & Bt176 & 0 & 0 & 0 & $?$ & 0 & 23280 & 0 & 0 & 0 & 0 & 0 & 0 & 0 & 23280 \\
\hline & MON810 & 0 & 0 & 0 & $?$ & 0 & 0 & 0 & 10 & 0 & 0 & 0 & 0 & 0 & 10 \\
\hline & Total & 0 & 0 & 0 & $<100$ & 2 & 23280 & 15 & 10 & 1 & 0 & 0 & 0 & 0 & 23390 \\
\hline \multirow[t]{3}{*}{2003} & Bt176 & 0 & 0 & 0 & $?$ & +1 & 26090 & 0 & 0 & 0 & 0 & 0 & 0 & 0 & 26090 \\
\hline & MON810 & 0 & 0 & 0 & $?$ & +4 & 6070 & 0 & 17 & 0 & 0 & 0 & 0 & 0 & 6087 \\
\hline & Total & 0 & 0 & 0 & $<100$ & 7 & 32160 & 15 & 17 & 1 & 0 & 0 & 0 & 0 & 32277 \\
\hline \multirow[t]{3}{*}{2004} & Bt176 & 0 & 0 & 0 & $?$ & $+2,-1$ & 21810 & 0 & 0 & 0 & 0 & 0 & 0 & 0 & 21810 \\
\hline & MON810 & 0 & 0 & 0 & $?$ & +7 & 36410 & 0 & 15 & 0 & 0 & 0 & 0 & +17 & 36425 \\
\hline & Total & 0 & 0 & 0 & $<100$ & 15 & 58220 & 15 & 15 & 1 & 0 & 0 & 0 & 17 & 58335 \\
\hline \multirow[t]{3}{*}{2005} & Bt176 & 0 & 0 & 0 & 0 & -4 & 0 & 0 & 0 & 0 & 0 & 0 & 0 & 0 & 0 \\
\hline & MON810 & 0 & 270 & +3 & 340 & +14 & 53225 & 0 & 493 & 0 & 0 & 0 & 760 & +14 & 55088 \\
\hline & Total & 0 & 270 & 3 & 340 & 25 & 53225 & 15 & 493 & 1 & 0 & 0 & 760 & 31 & 55088 \\
\hline \multirow[t]{3}{*}{2006} & Bt176 & 0 & 0 & 0 & 0 & 0 & 0 & 0 & 0 & 0 & 0 & 0 & 0 & 0 & 0 \\
\hline & MON810 & 0 & 1290 & +2 & 954 & +11 & 53667 & 0 & 5028 & 0 & $<10$ & 0 & 1254 & 0 & 62203 \\
\hline & Total & 0 & 1290 & 5 & 954 & 36 & 53667 & 15 & 5028 & 1 & $<10$ & 0 & 1254 & 31 & 62203 \\
\hline
\end{tabular}

Abbreviations: $\mathrm{CZ}=$ the Czech Republic; $\mathrm{DE}=$ Germany; $\mathrm{ES}=$ Spain; FR $=$ France $\mathrm{NL}=$ the Netherlands; $\mathrm{PT}=\mathrm{Portugal}$. * 23/01/1997: EU approval for the event Bt176 pursuant to Directive 90/220/EEC (Commission Decision 97/98/EC).

** 22/04/1998: EU approval for the events MON810 and T25 pursuant to Directive 90/220/EEC (Commission Decisions 98/294/EC and 98/293/EC, respectively).

*** Registration of Chardon LL derived from the transgenic event T25. 
and socio-economic issues in the risk analysis of GM agro-food products. The 'Norwegian Gene Technology Acts' (Myhr and Traavik, 2003) and 'Swedish Environmental Code' (Karlsson, 2003a), for instance, require that (1) "the use of GM crops takes place in an ethical and socially justifiable way, in accordance with the principle of sustainable development"; and that (2) "the release represents a benefit to the community". In the Netherlands, an 'integrated framework for the assessment of social and ethical issues in modern biotechnology' was elaborated (COGEM, 2003). The Belgian ad hoc committee 'Sustainability and ethical aspects' was established in 2003 to provide a wider assessment of the experimental release demand of a transgenic apple tree. However, in most of these cases, MS seemed to experience difficulties in securing the conversion of societal concerns into concrete action.

\section{Restyling II: Regulation 178/2002 concerning the general principles and requirements of food law, the establishment of the European Food Safety Authority (EFSA), and the procedures in matters of food safety}

Adding on to Directive 2001/18, Regulation 178/2002 lays down the general principles of food law and procedures in food and feed safety, as well as the tasks of the EFSA. With this Regulation, the application of the PP is further extended to the risk analysis of all food and feed in the EU, whether or not of GM origin. A uniform basis for the adoption of the PP is provided by stating that "in specific circumstances where, following an assessment of available information, the possibility of harmful effects on health is identified, but scientific uncertainty persists, provisional risk management measures necessary to ensure the high level of health protection chosen in the Community may be adopted, pending further scientific information for a more comprehensive risk assessment". The adopted PP measures shall be "proportionate and no more restrictive of trade than is required to achieve the high level of health protection chosen" and "reviewed within a reasonable period of time".

In response to a multiple wave of food crises that caused considerable concerns in European publics about food safety and the ability of regulatory authorities to fully protect consumers, the EFSA was created as a Europeanwide risk assessment body. By providing 'independent, objective and transparent' science-based advice, the EC hoped that the EFSA would facilitate EU decisions and help restoring consumers' confidence. As such, it has to reconcile diverse views through its own expert advice. These complicated objectives have not yet been achieved: some MS continue to dissent from EFSA opinions, EC decision proposals gain little support from MS, and the regulatory-expert conflicts continue to undermine public credibility in EU science-based policy (Levidow and Carr, in press).

\section{Restyling III: Regulation 1829/2003 on genetically modified food and feed}

Since 18 April 2004, Regulation 1829/2003 covers the commercialization and safety assessment of GM food and feedstuffs, e.g. food/feed containing or consisting of GMOs, food/feed produced from GMOs, and food containing ingredients produced from GMOs. Prior to this date, consents for human food use were required under the Novel Food Regulation, whereas feed uses were assessed under Directive 2001/18 and its predecessor. Products that have been lawfully placed on the European market continue, in accordance to Regulation 641/2004, to be allowed on the market as long as they were notified to the EC before 18 October 2004. The authorized agro-food products enter in a Community Register of GM food and feed, which is made available to the public. The changes introduced by this GM Food and Feed Regulation are discussed in the following sections.

\section{A centralized 'one door-one key' authorization procedure}

To improve the safety standards of GM agro-food products, and to facilitate EU decisions, a new authorization procedure was put in place. On the one hand, this procedure is centralized around the EFSA. In addition to centralizing administrative procedures, the EFSA is in charge of harmonizing risk assessment criteria across MS. In this process, a wide range of experts and actors are consulted (EFSA, 2004b). MS are specifically consulted on notifications to positively integrate their views in the EFSA opinions. However, in practice, only 'reasonable' demands are accepted, whilst those that fall outside the scope of the risk discourse are dismissed on the grounds that they are not scientific. As such, the more precautionary approaches developed by some MS are hardly accommodated.

On the other hand, this procedure is based on a 'one door-one key' approach whereby all the commercial uses can be covered in a same dossier. Compared to the procedures of Directive 2001/18 and Regulation 258/97, this provides a much more streamlined and less cumbersome authorization procedure. Moreover, it avoids the granting of consent for a single use, while a product is likely to be used both for food and feed purposes. This was the case in the StarLink affair. The maize CBH-351 event (also called StarLink) was only approved for animal feed. Nonetheless, in September 2000, traces of it were found 
Societal concerns and EU regulatory frame on GM crops

in food products destined for human consumption in the United States (US) (Demeke et al., 2006).

\section{Safety assessment}

In response to the heated debates that challenged the principle of substantial equivalence, the principle was demoted to a comparative analysis in the GM Food and Feed Regulation. The safety assessment of GM food and feed remains based on a comparative analysis in which the non-GM counterpart serves as baseline. However, it requires more evidence of safety than before; more scientific uncertainties are addressed, and the principle can no longer be used to justify the claim that a risk assessment is unnecessary (Levidow et al., 2007). This trend stems from the evolving interpretation given to the principle of substantial equivalence over time. Since the principle was intensely criticized by various actors, it was no longer interpreted as the end point of risk assessment, but rather as the starting point. Whether the GM food was subjected to further safety assessment depended on the identified differences between the GM food and its comparator: (1) if substantial equivalence was established, the need for further testing was investigated on a case-by-case basis; (2) if substantial equivalence was established except for a single or few specific traits of GM crops, further tests were done focusing on these traits; and (3) if neither partial nor total substantial equivalence was established, the wholesomeness of the food product was assessed. In the same line of arguments, the simplified procedure was abandoned under the GM Food and Feed Regulation.

The EC's Joint Research Centre was established as the new Community Reference Laboratory for the technical evaluation and validation of sampling, identification and detection methods for GM agro-food products, which is crucial information for controlling the correct implementation of EU labeling requirements.

\section{Labeling}

The labeling provisions of all material intentionally consisting of, containing GM crops or products derived from them are firmly enshrined by the GM Food and Feed Regulation. This Regulation extended these provisions to feeds, seeds, bulk products, foods that are delivered as such to the final consumers or mass caterers, and to products in which GMO-derived DNA or protein is no longer detectable. These requirements go further than the previous ones, because the use of genetic modification in itself now is sufficient to justify labeling. The label must be shown in a clearly visible, legible and indelible manner, and contain the reference 'genetically modified', 'produced from genetically modified' or 'contains genetically modified'. When a GM food or feed is different from its conventional counterpart, the label must also provide information about any characteristic or property that renders it different. When there is no conventional counterpart, the label must contain appropriate information about the nature and the characteristics of the GM food or feed. Any characteristic or property that gives rise to ethical or even religious concerns also has to be mentioned. Unfortunately, no further clarifications are given on the meaning of ethical or religious concerns, making this aspect of the new regulation on labeling extremely relative.

Although this point was the target of criticism of NGOs, products being produced with the help of GMOs rather than actually made out of them - do not require labeling. As such, meat, eggs, milk and dairy products from animals reared with GM feed fall beyond the remit of labeling provisions. In contrast, other actors considered the need to label products that do not contain DNA or protein traces as too excessive. Since substances assisting in food production, carrier substances or culture media for micro-organisms are not considered foods, their labeling is not considered necessary (CEC, 2006).

\section{Adventitious GMO presence in non-GM material}

Reviewing twenty years of experience with transgene containment, Marvier and Van Acker (2005) inferred that the movement of transgenes beyond their intended destinations is a virtual certainty. Traces of unapproved GM crop events have been observed in commercially certified seeds, grains and foodstuffs (Demeke et al., 2006; Friesen et al., 2003; Vogel, 2006), as well as in feral oilseed rape populations located in ports, and along transportation routes (Saji et al., 2005; Yoshimura et al., 2006). Various sources can be at the origin of adventitious mixing between GM and non-GM material: the use of impure seed, the natural pollen flow between neighboring fields, the occurrence of volunteer plants originating from seeds and/or vegetative plant parts from previous crops, the human activities during sowing, harvesting, handling, transporting, storing, importing and processing, and to a lesser extent the presence of certain sexually compatible wild relatives and feral plants (Devos et al., 2004, 2005). Because of this, keeping transgenes on a leash is difficult. In order to cope with this problem, tolerance thresholds were established for the unintentional or technically unavoidable presence of authorized GM material in nonGM products in the EU.

A tolerance threshold refers to the maximum admixture level for GM content under which the co-mingled product does not have to be labeled as being consisting of, containing or produced from a GMO. More specifically, Regulation 49/2000 set the labeling threshold for 
the adventitious GMO presence in non-GM foodstuffs at $1 \%$ of the food ingredient. Regulation 1829/2003 decreased the tolerance threshold to $0.9 \%$, and extended it to feed and products intended for direct processing. There is zero tolerance for EU unapproved events, unless they received a favorable scientific risk assessment for marketing and a detection method is publicly available. In the latter case, a threshold of $0.5 \%$ may be applied transitionally.

For seeds and organic production, a threshold for GM content is still lacking, as discussions remained at an impasse. Possible thresholds that will be proposed for seeds will be established at levels such that the GM content of $0.9 \%$ can be guaranteed in food, feed or crops. Proposals range between $0.3 \%$ for cross-pollinating crops, and $0.5 \%$ for self-pollinating and vegetatively propagated crops (SCP, 2001). As no thresholds for the adventitious GMO presence in non-GM seeds have been established to date, any seed lot containing authorized GM seeds destined for cultivation in the EU has to be labeled as containing GMOs.

Organic growers prefer a zero tolerance: Regulation 1804/1999 states that the use of GMOs and their derivatives is not compatible with the organic production method. However, due to the foreseen de minimis threshold for unavoidable contamination, it may be assumed that a level between the limit of quantification of a DNA analysis $(0.1 \%)$ and $0.9 \%$ might be defined in due time by each MS. Moreover, the EC press release of 21 December 2005 emphasizes that an organic product with an adventitious GMO content below $0.9 \%$ can still be labeled as organic.

It is often argued that there is no scientific justification for the established thresholds. Since GM agro-food products are declared safe before marketing, thresholds are not related to safety or health issues. However, they reflect a balance between differently framed requests and technical capabilities (the lower the threshold, the larger the error): notifiers request high thresholds, whilst NGOs and consumers demand lower ones. Still, the translation of labeling thresholds in practice entails enormous technical and scientific challenges (Holst-Jensen et al., 2006; Miraglia et al., 2004; Weighardt, 2006).

\section{Co-existence between GM and non-GM crops}

As we saw, keeping transgenes on a leash is difficult. To manage this problem of adventitious mixing, a co-existence policy was introduced through an amendment of Regulation 1829/2003 to Directive 2001/18. Coexistence refers to the ability of farmers to make a practical choice between conventional, organic and GM crop production. More specifically, it has been decided that all cropping systems should be possible, and that the presence of one system should not exclude other systems in the neighborhood. The ability to maintain different agricultural production systems is also a prerequisite for providing a high degree of consumer choice, which is achievable by segregation and identity preservation systems, and through traceability and labeling provisions. Within this context, labeling thresholds play a crucial role, since harm resulting from adventitious mixing will only be actionable if a certain threshold is exceeded. Moreover, thresholds will define the required level of containment. Hence, the efforts needed to meet these thresholds will inevitably affect farming and the supply chain management (Devos et al., 2007).

The co-existence between cropping systems is framed by the EU as a socio-economic problem arising from the growing of commercially approved GM crops. Since these crops were judged as safe, biosafety issues fall beyond the remit of co-existence. Although the processes of vertical gene flow are similar, the context differs (Schiemann, 2003). Various actors heavily criticize this distinction: they perceive GM crops as a threat to other crop productions and even to ecologically sensitive regions (Altieri, 2005; Verhoog et al., 2003).

Due to the heterogeneity in farm structures, crop patterns and legal environments between MS, the EC followed the principle of subsidiarity for the implementation of legal co-existence frames. However, with the empowerment of local authorities, the governance of GM crops was extended to additional players, further complicating its organization. To avoid the proliferation of too diverse co-existence standards over the EU, and to secure its predefined co-existence scope, the EC guidelines (2003/556) for the development of national strategies and practices were elaborated. In these guidelines, the "newcomer pays principle' was accommodated with GM production as the 'newcomer'. Hence, GM growers may be required to pay suitable restitution when they cause unlawful damages through intentional or negligent actions and/or fail to take adequate preventive measures to maintain adventitious mixing below the tolerance thresholds.

Moreover, through the notification procedure of Directive 98/3, the EC assesses whether the national/regional legal proposals for co-existence are in conformity with Community legislations. Preliminary assessments indicate that the co-existence debate broadened the range of relevant policy uncertainties, further blurring any distinction between economic, agricultural and environmental harms. As such, some legal proposals favor certain cropping systems over others. That the legal criterion for co-existence was adopted in the environmental Directive 2001/18 may have contributed to this blurring (EC, 2006; Levidow and Boschert, in press). 
Societal concerns and EU regulatory frame on GM crops

\begin{abstract}
Restyling IV: Regulation 1830/2003 concerning the traceability and labeling of genetically modified organisms and the traceability of food and feed products produced from genetically modified organisms
\end{abstract}

Regulation 1830/2003 complements, clarifies and makes operational some of the labeling and traceability objectives of previous legislations. With the labeling provisions of the Novel Food Regulation, the need for traceability 'from farm to fork' was indirectly introduced. According to Huffman (2004), "a labeling policy may not be effective without maintaining different agricultural production systems, and segregating and tracing of GM products". It is Directive 2001/18 that introduced the general principle of traceability at all stages of the placing on the market of GM products. The aim is to provide the ability to retrieve the history and use or location of a GM product through a registered identification: specific information on the GMO will be transmitted and retained (for a period of five years) throughout the production and supply chains, which allows tracking GMO products' movements. This information can be accessed via a specific code that is attributed to each GMO from the Community register, which will act as a unique identifier. Under the auspices of the Organization for Economic Cooperation and Development a system for unique identifiers for GM crops was developed and recently enforced by Regulation 65/2004 at European level (Lezaun, 2006).

In addition to the prerequisite for labeling, traceability offers the possibility to withdraw products that have an unexpected adverse effect to human health or the environment. In this view, traceability may be seen as a valuable tool for environmental and health protection, as well as for monitoring. Moreover, the preamble of Regulation 1830/2003 mentions that "traceability should facilitate the implementation of risk management measures in accordance with the PP". The products concerned by the labeling requirements are pre-packaged products consisting of or containing GMOs, and non-pre-packaged products sold to the final consumers.

\section{WILL GM CROPS SPREAD IN THE EUROPEAN MARKET AFTER THE MORATORIUM?}

The regulatory changes discussed above contributed to the abandon of the de facto EU moratorium in 2004. As a result, new EC market consents were granted for several pending notifications, albeit not without discord. Moreover, the freshly granted market consents only covered food, feed, import and industrial processing, meaning that most of the approved transgenic crops are still cultivated outside the EU, subsequently imported and eventually further processed in the EU. With the submission of notifications covering the marketing of GM stacked events, today this trend continues (De Schrijver et al., 2007). For example, a first GM stacked event, MON810 × MON863 maize has been approved under Directive 2001/18 for import and industrial processing on 13 January 2006. Products derived from an increasing diversity of GM events thus may be expected in the European supply chains and retail shelves. Still, a recent qualitative survey of GM food labels in French supermarkets revealed that there are almost no GM-labeled products on supermarkets' shelves (Gruère, 2006), suggesting that food processors are still avoiding these products in favor of non-GM alternatives, or that they only use products in which the GMO content is kept under the labeling threshold. The few GM foodstuffs that do reach the retail shelves are also likely to be targeted by pressure groups opposed to genetic modification (Carter and Gruère, 2003). Retailers avoid GM products, and ever since 1999, a non-GM European food market has been induced by public protest combined with legal labeling and traceability provisions. There is little doubt that GM crops have been imported mainly as feed and/or have been processed in feed mixtures for cattle and poultry (CEC, 2006; Gryson et al., 2007). Indeed, as we saw, products obtained from animals fed with GM crops do not require labeling, and as such, escape the debate.

The cultivation of new GM crop events also remains far on the horizon in the EU. On 7 December 2005, the EFSA adopted a first positive opinion for cultivation of the GM potato event EH92-527-1. However, its cultivation will be restricted to a closed loop system of contractors (EFSA, 2006b). Moreover, the European adoption rate of previously approved GM crops for cultivation was slow (Demont and Tollens, 2004). With the registration of seventeen MON810 hybrids in the common seed catalogue on 8 September 2004, the GM maize cultivation area increased in France, Germany and Spain, and expanded to the Czech Republic and Portugal in 2005. Nonetheless, in 2005, the European cultivation area of GM maize was approximately 55000 ha, whilst globally 21.2 million ha was reached. The registration of other, more regionally adapted MON810 hybrids in the German, Spanish and common EU catalogue soon followed. These evolutions may increase the adoption of the transgenic insect resistant hybrids, especially in regions where the European and/or Mediterranean corn borer are pests, although this boost may be counterbalanced by legal co-existence constraints and high premium prices of transgenic seeds (Tab. 3).

\section{CONCLUSION}

In general, it has been argued that the de facto moratorium on GM crops in the EU gave room to a broader discussion, adding a societal orientation to the existing 
Y. Devos et al.

frame. This discussion has been translated into a thorough renewal of the regulatory frame on GM agro-food products. The move to cover and embrace societal concerns led to a regulatory regime that imposes the most stringent criteria for their approval worldwide ( $c f$. WTO dispute between the US and EU). The debates on and evolutions in the regulatory frame continue to reflect societal concerns relating to GM agro-food products to various degrees.

Still, estimating to what extent the regulatory changes by themselves are helpful in pacifying the underlying conflict on GM agro-food products in the EU is not easy. This has much to do with the fact that the public perceive risks differently than scientific experts and risk assessors. Moreover, with the installation of an explicit non-GM food market in the EU since 1999, it has become difficult to estimate whether members of the public will behave as consumers rather than as citizens, and let price, packaging, availability, the convenience of preparation, brand names and/or other moral concerns determine their choices to buy or not GM agro-food products. Generally, "surveys place respondents in the role of citizens, who make judgments from society's point of view, rather than consumers, who make actual purchase decisions" (Brom, 2000; Noussair et al., 2004). Even then, the acceptability of buying those products continues to show a large degree of heterogeneity within EU countries (Lusk et al., 2006; Spence and Townsend, 2006).

It has been shown how, in response to the societal concerns about harmfulness and scientific uncertainties of GM agro-food products, various scientific and technical reforms were made at the level of the risk analysis. In this context, first, the environmental risk analysis was differentiated from product-specific risk analyses. Second, the PP was explicitly adopted in 2002 to cope with scientific uncertainties. Consequently, the scope of the ERA was broadened to include more agro-ecological expertise, attempts were made to render value judgments and the limitations of risk assessment more explicit, the environmental PMM and traceability became mandatory, the use of certain ARM genes was phased out, and the duty of re-examination of risk analysis was strengthened by limiting the duration of market consent to ten years. Third, risk assessment methodologies and approaches were harmonized, and new institutes such as the EFSA were created to provide independent, objective and transparent science-based advice. A centralized one door-one key approach authorization procedure was implemented to avoid the adventitious presence of non-authorized GM material in other produces. Fourth, openings were created for public participation and ethical consultation in the authorization procedure.

Labeling, traceability and public information/registers formed a legal answer to the general desire of the public for more information about GM agro-food products, and the specific demand to respect the consumers' freedom of choice. Labeling indeed allows consumers to make an informed choice about buying GM agrofood products. However, labeling may be inappropriate in some cases, because those who consume the food do not necessarily buy it. In the EU, there has been an evolution towards more stringent labeling of all materials 'intentionally consisting of, containing GM crops or products derived from them'. Nowadays, the sole use of genetic modification is sufficient to justify labeling, meaning that even products in which no GMO traces are detectable, have to be labeled. In addition to guaranteeing a high degree of consumers' choice, the freedom of choice of farmers to cultivate or not GM crops, as well as the maintenance of agricultural diversity are ensured through coexistence.

Despite the apparent progress towards a more sensitive evaluation of GM agro-food products, the societal disjuncture continues. First, safety issues still occupy a prominent position in the risk analysis of GM crops, and restrictions to market consents are only applied when harm to human health and the environment is at stake. The legal reforms solidified the science-based policy by further reducing societal concerns to biosafety risks. That several concerns about safety have been taken seriously may reassure some members of the public. However, it is not clear whether increased safety assurances based on risk assessments alone make some members of the public feel any safer. As we saw, lay people widely expand the concept of risk. Based on the results of the latest Eurobarometer survey, Gaskell et al. (2006) observed that "the new regulatory frame appears to have done little to allay the European public's anxieties about agro-food biotechnology", suggesting that "the years of controversy have led many people in Europe to believe that anything to do with GM food is undesirable". Other research on public attitudes towards GM agro-food products gives indications in this direction. It is suggested that, next to risk perception, perception of potential benefits is also determinant for acceptance. Potential risks are weighed against potential benefits. For a large group, risks even hardly appear to play a role. In this case, benefits or the absence thereof seem to be the decisive factor (Gaskell et al., 2004). The bottleneck is that the European regulatory frame on GM crops does not offer the possibility to consider potential benefits in the actual risk analysis. There is no legal room to evaluate whether GM crops fulfill wider socio-economic and environmental aspirations. It is not possible to evolve towards a sustainability assessment. Moreover, as the use of the PP is kept within a narrow scientific context, its linkage to the ideal of sustainable development is hampered. 
Second, the implementation of labeling, in fact leaves societal and political choices regarding the consumption of GM agro-food products to the individual. Intrinsic moral concerns regarding genetic modification remain unaddressed in the authorization procedure. Opponents to genetic modification can only avoid GM-labeled products that are on the market: 'to buy or not to buy' is their sole political power.

Third, some openings have been created, offering the possibility to assess concerns that are explicitly labeled as ethical. However, these openings seem to be merely symbolic, since the ethical assessment is not supposed to change the consent procedure or content, and remains difficult to implement. This is in analogy with the public consultations where only scientific and technical comments are considered, and where larger societal concerns are a priori excluded. Practical problems in making this opening workable (towards direct public engagement and towards the inclusion of societal concerns in authorization procedures) can be invoked. However, it may also reflect the difficulty to make narrow and stringent legal frames coincide fully with complex, broad and often fluctuating ethical concerns. That many societal concerns are not related to GM crops alone, but questions the whole agricultural system - of which GM crops only represent the tip of the iceberg - is illustrative of this.

Fourth, the societal disjuncture regarding GM agrofood products did not dissipate with the various institutional reforms that led to the upheaval of the de facto moratorium in 2004. To the contrary, "the prevalent harmonization strategy aggravated EU-national disharmonies rather than reduced them" (Levidow and Carr, in press). Following investigations of safeguard clause demands made by MS, the EFSA generally concluded that there is no new information invalidating the contested risk assessment or justifying a prohibition, since geographical, ecological or nutritional particularities are generally ascertained in risk assessments (EFSA, 2006c). Moreover, recent market consents were not granted without discord. MS still raise various safety objections, continuing to adopt more stringent criteria than EU institutions. Consequently, a qualified majority is rarely reached at the Council of Ministers. However, despite the many national objections and limited support from MS, the EC generally adopts decisions based on the favorable risk assessment of the EFSA at the end of the authorization procedure. Although the EC seldom disregards the EFSA opinions, Stavros Dimas - who represents the Environment Directorate General of the EC - requested a more thorough assessment of potential long-term effects of GM crops at the Vienna conference on the co-existence of genetically modified, conventional and organic crops held in April 2006. Moreover, under the pressure of the growing dissatisfaction of some MS, the EC recently asked the
EFSA to provide greater transparency about value judgments and scientific uncertainties in risk assessments, and to develop a greater consensus between all interested actors (CEC, 2006; Levidow, 2006). In addition to increasing the transparency in and scientific consistency of risk assessments, the EFSA recently committed itself to reinforce the collaboration with MS (EFSA, 2006d).

Fifth, the conflict itself is dynamic, and currently seems to shift to new topics and domains. With the currently implemented or proposed co-existence frames in some MS, the heated debates related to the labeling thresholds for seeds and organic produce, and the vigorous movement in quest of creating GM-crop-free zones all over the EU, co-existence seems to be used as a pretext for placing new barriers on the path of GM crops. Moreover, transferring authority to local actors complicated further the governance of GM crops, blurring any distinction between environmental, economic and agricultural uncertainties.

The GM crop controversy will inevitably be stirred up by new triggers if, for example, traces of authorized GM crop events in organic products or of unapproved GM crop events in conventional products ( $c f$. Bt10 maize, LL601 rice) are found anew. Much depends on how such triggers will be interpreted in the contemporary legal and societal climate (Nisbet and Huge, 2006).

In sum, the EU regulatory frame on GM agro-food products currently aims at a pragmatic balance between various legal objectives. In this, only a fraction of the societal concerns are embraced. Safety issues and the creation of an internal market stand in the focus of the EU legislation, whilst the remaining concerns are diverted to the private sphere through labeling. Today, the explicit role of public participation and/or of ethical consultation during authorization procedures is at best symbolic. Hence, there is barely a move to evolve from "reliable expertise" towards "socially robust expertise" (Nowotny, 2003). However, the recent policy shift towards greater transparency about value judgments, diverse viewpoints and scientific uncertainties in risk assessments may be one step forward in establishing more modest and pluralistic expertise. Still, it remains to be seen how this policy shift will be translated in practice at the EU level, and if it will help reaching greater consensus among all interested actors.

Currently, there is no room to implement an integral sustainability evaluation during market procedures. This makes it impossible to trade possible risks against benefits, to compare technological alternatives, to test the usefulness, and to assess the whole agricultural system, thereby integrating larger societal concerns. Such an approach may promote a better balance between agricultural production and biodiversity, and may more explicitly encompass the broader-than-scientific dimension of actual risk analysis. Out of these discussions will 
follow whether the implementation of an integral sustainability evaluation is desirable, feasible and operational, and whether it should be limited to GM crops alone.

Received August 7, 2006; accepted December 30, 2006.

\section{REFERENCES}

ACRE (2004a) Advice on the implementation of the farm-scale evaluations of genetically modified herbicide-tolerance crops, http://www.defra.gov.uk/Environment/acre/advice/pdf/ acre_advice44.pdf

ACRE (2004b) Guidance on best practice in the design of post-market monitoring plans in submissions to the Advisory Committee on Release to the Environment, http://www.defra.gov.uk/environment/acre/postmarket/ acre_postmarketmonitor-guidance.pdf

ACRE (2005) Advice on the implementation of the farm-scale evaluations of genetically modified herbicide-tolerance winter oilseed rape, http://www.defra.gov.uk/Environment/acre/ advice/pdf/acre_advice65.pdf

ACRE (2006) Managing the footprint of agriculture: towards a comparative assessment of risks and benefits for novel agricultural systems, http://www.defra.gov.uk/environment/acre/ fsewiderissues/acre-fse-060317draft.pdf

Altieri MA (2005) The myth of coexistence: why transgenic crops are not compatible with agroecologically based systems of production. B. Sci. Technol. Soc. 25: 1-11

BAC (2004) Advice on the British report 'On the rationale and interpretation of the Farm-Scale Evaluation (FSE) of genetically modified herbicide-tolerant (GMHT) crops', http://www.bio-council.be/docs/BAC_2004_SC_087.pdf

Bennett PM, Livesey CT, Nathwani D, Reeves DS, Saunders JR, Wise R (2004) An assessment of the risks associated with the use of antibiotic resistance genes in genetically modified plants: report of the working party of the British society for antimicrobial chemotherapy. J. Antimicrob. Chemother. 53: 418-431

Bonneuil C, Joly PB, Marris C (in press) Disentrenching experiment? The construction of GM-crop field trials as a social problem in France. Sci. Tech. Human Values

Brom FWA (2000) Food, consumer concerns, and trust: food ethics for a globalizing market. J. Agric. Environ. Ethics 12: 127-139

Carr S (2002) Ethical and value-based aspects of the European Commission's precautionary principle. J. Agric. Environ. Ethics 15: 31-38

Carr S, Levidow L (2000) Exploring the links between science, risk, uncertainty and ethics in regulatory controversies about genetically modified crops. J. Agric. Environ. Ethics 12: 29-39

Carter CA, Gruère GP (2003) Mandatory labeling of genetically modified foods: does it really provide consumer choice? AgBioForum 6: 68-70

CEC (2000) Communication from the Commission on the precautionary principle, http://europa.eu.int/comm/dgs/health_ consumer/library/pub/pub07_en.pdf
CEC (2006) Report from the Commission to the Council and the European Parliament on the implementation of Regulation (EC) No 1829/2003 of the European Parliament and of the Council on genetically modified food and feed

Chamberlain DE, Fuller RJ, Bunce RGH, Duckworth JC, Shrubb M (2000) Changes in the abundance of farmland birds in relation to the timing of agricultural intensification in England and Wales. J. Appl. Ecol. 37: 771-788

Chapman MA, Burke JM (2006) Letting the gene out of the bottle: the population genetics of genetically modified crops. New Phytol. 170: 429-443

Chassy B, Carter C, McGloughlin M, McHughen A, Parrott W, Preston C, Roush R, Shelton A, Strauss SH (2003) UK field-scale evaluations answer wrong questions. Nat. Biotechnol. 21: 1429-1430

Christoforou T (2004) The regulation of genetically modified organisms in the European Union: the interplay of science, law and politics. CML Rev. 41: 637-709

COGEM (2003) Towards an integrated framework for the assessment of social and ethical issues in modern biotechnology, http://www.cogem.net/pdfdb/advies/CGM03061802UK.pdf

Cook G, Pieri E, Robbins PT (2004) 'The scientists think and the public feels': expert perceptions of the discourse of GM food. Discourse Soc. 15: 433-449

Cook G, Robbins PT, Pieri E (2006) "Words of mass destruction": British newspaper coverage of the genetically modified food debate, expert and non-expert reactions. Public Underst. Sci. 15: 5-29

de Sadeleer N (2006) The precautionary principle in the EC health and environmental law. ELJ 12: 139-172

De Schrijver A, Devos Y, Van den Bulcke M, Cadot P, De Loose M, Reheul D, Sneyers M (2007) Risk assessment of GM stacked events obtained from crosses between GM events. Trends Food Sci. Technol. 18: 101-109

Deblonde M, du Jardin P (2005) Deepening a precautionary European policy. J. Agric. Environ. Ethics 18: 319-343

Deckers J (2005) Are scientists right and non-scientists wrong? Reflections on discussions of GM. J. Agric. Environ. Ethics 18: $451-478$

Demeke T, Perry DJ, Scowcroft WR (2006) Adventitious presence of GMOs: scientific overview for Canadian grains. Can. J. Plant Sci. 86: 1-23

Demont M, Tollens E (2004) First impact of biotechnology in the EU: Bt maize adoption in Spain. An. Appl. Biol. 145: $197-$ 207

Devos Y, Reheul D, De Schrijver A, Cors F, Moens W (2004) Management of herbicide-tolerant oilseed rape in Europe: a case study on minimizing vertical gene flow. Environ. Biosafety Res. 3: 135-148

Devos Y, Reheul D, De Schrijver A (2005) The co-existence between transgenic and non-transgenic maize in the European Union: a focus on pollen flow and cross-fertilization. Environ. Biosafety Res. 4: 71-87

Devos Y, Reheul D, Thas O, De Clercq EM, Cougnon M, Cordemans K (2007) Implementing isolation perimeters around genetically modified maize fields. Agron. Sustain. Dev., doi:10.1051/agro:2006005 
EC (2006) Report on the implementation of national measures on the co-existence of genetically modified crops with conventional and organic farming, http://europa.eu.int/comm/agriculture/coexistence/ index_en.htm

EFSA (2004a) Opinion of the scientific panel on genetically modified organisms on the use of antibiotic resistance genes as marker genes in genetically modified plants. EFSA J. 48 : $1-18$

EFSA (2004b) Guidance document of the scientific panel on genetically modified organisms for the risk assessment of genetically modified plants and derived food and feed. EFSA $J$. 99: $1-94$

EFSA (2006a) Opinion of the scientific panel on genetically modified organisms on the post market environmental monitoring (PMEM) of genetically modified plants. EFSA J. 319: $1-27$

EFSA (2006b) Opinion of the scientific panel on genetically modified organisms on a request from the Commission related to the notification $(\mathrm{C} / \mathrm{SE} / 96 / 3501)$ for the placing on the market of genetically modified potato EH92-527-1 with altered starch composition, for cultivation and production of starch, under Part C of Directive 2001/18/EC from BASF Plant Science. EFSA J. 323: 1-20

EFSA (2006c) Opinion of the scientific panel on genetically modified organisms on a request from the Commission related to genetically modified crops (Bt176 maize, MON810 maize, T25 maize, Topas 19/2 oilseed rape and MS1 $\times$ RF1 oilseed rape) subject to safeguard clauses invoked according to Article 16 of Directive 90/220/EEC. EFSA J. 338: 1-15

EFSA (2006d) Transparency in risk assessment carried out by EFSA: guidance document on procedural aspects. EFSA $J$. 353: $1-16$

EGE (1995) Opinion of the group of advisers on the ethical implications of biotechnology to the European Commission on the ethical aspects of the labelling of foods derived from modern biotechnology, http://ec.europa.eu/european_group_ ethics/docs/opinion5_en.pdf

Firbank L, Lonsdale M, Poppy G (2005) Reassessing the environmental risks of GM crops. Nat. Biotechnol. 23: 1-2

Frewer L, Lassen J, Kettlitz B, Scholderer J, Beekman V, Berdal KG (2004) Societal aspects of genetically modified food. Food Chem. Toxicol. 42: 1181-1193

Friesen LF, Nelson AG, Van Acker RC (2003) Evidence of contamination of pedigreed canola (Brassica napus) seedlots in western Canada with genetically modified herbicide resistance traits. Agron. J. 95: 1342-1347

Gaskell G, Allum N, Wagner W, Kronberger N, Torgersen H, Hampel J, Bardes J (2004) GM foods and the misperception of risk perception. Risk Anal. 24: 185-194

Gaskell G, Allansdottir A, Allum N, Corchero C, Fischler C, Hampel J, Jackson J, Kronberger N, Mejlgaard N, Revuelta G, Schreiner C, Stares S, Torgersen H, Wagner W (2006) Europeans and Biotechnology in 2005: Patterns and Trends, Eurobarometer 64.3, http://www.ec. europa.eu/research/press/2006/pdf/pr1906_eb_64_3_final_ report-may2006_en.pdf
Genus A, Coles AM (2005) On constructive technology assessment and limitations on public participation in technology assessment. Tech. Anal. Strat. Manage. 17: 433-443

Goldstein DA, Tinland B, Gilbertson LA, Staub JM, Bannon GA, Goodman RE, McCoy RL, Silvanovich A (2005) Human safety and genetically modified plants: a review of antibiotic resistance markers and future transformation selection technologies. J. Appl. Microbiol. 99: 7-23

Gottweis H (2005) Transnationalizing recombinant-DNA regulation: between Asilomar, EMBO, the OECD, and the European Community. Sci. Cult. 14: 325-338

Gruère GP (2006) A preliminary comparison of the retail level effects of genetically modified food labelling policies in Canada and France. Food Policy 31: 148-161

Gryson N, Messens K, Van Laere D, Eeckhout M (2007) Coexistence and traceability of GM and non-GM products in the feed chain. Eur. Food Res. Technol., doi: 10.1007/s00217006-0511-x

Guehlstorf NP, Hallstrom LK (2005) The role of culture in risk regulations: a comparative case study of genetically modified corn in the United States of America and European Union. Environ. Sci. Policy 8: 327-342

Hails RS, Morley K (2005) Genes invading new populations: a risk assessment perspective. Trends Ecol. Evol. 20: 245-252

Heller C (2002) From scientific risk to paysan savoir-faire: peasant expertise in the French and global debate over GM crops. Sci. Cult. 11: 5-37

Hill RA (2005) Conceptualizing risk assessment methodology for genetically modified organisms. Environ. Biosafety Res. 4: $67-70$

Hill RA, Sendashonga C (2003) General principles for risk assessment of living modified organisms: lessons for chemical risk assessment. Environ. Biosafety Res. 2: 81-88

Hoffmann-Riem H, Wynne B (2002) In risk assessment, one has to admit ignorance. Nature 416: 123

Holst-Jensen A, De Loose M, van den Eede G (2006) Coherence between legal requirements and approaches for detection of genetically modified organisms (GMOs) and their derived products. J. Agric. Food Chem. 54: 2799-2809

Huffman WE (2004) Production, identity preservation, and labeling in a marketplace with genetically modified and nongenetically modified foods. Plant Physiol. 134: 3-10

Irwin A (2006) The politics of talk: coming to terms with the 'new' scientific governance. Soc. Stu. Sci. 36: 299-320

Jensen KK (2002) The moral foundation of the precautionary principle. J. Agric. Environ. Ethics 15: 39-55

Jensen KK, Sandøe P (2002) Food safety and ethics: the interplay between science and values. J. Agric. Environ. Ethics 15: 245-253

Jensen KK, Gamborg C, Madsen KH, Jørgensen RB, Krayer von Krauss M, Folker AP, Sandøe P (2003) Making the EU "Risk Window" transparent: the normative foundation of risk assessment of GMOs. Environ. Biosafety Res. 2: 161171

Johnson KL, Raybould AF, Hudson MD, Poppy GM (2007) How does scientific risk assessment of GM crops fit within the wider risk analysis? Trends Plant Sci. 12: 1-5 
Y. Devos et al.

Kalaitzandonakes N, Bijman J (2003) Who is driving biotechnology acceptance? Nat. Biotechnol. 21: 366-369

Karlsson M (2003a) Ethics of sustainable development - a study of Swedish regulations for genetically modified organisms. J. Agric. Environ. Ethics 16: 51-62

Karlsson M (2003b) Biosafety principles for GMOs in the context of sustainable development. Int. J. Sust. Dev. World Ecol. 10: $15-26$

Karlsson M (2006) Science and norms in policies for sustainable development: assessing and managing risks of chemical substances and genetically modified organisms in the European Union. Regul. Toxicol. Pharmacol. 44: 49-56

Kok EJ, Kuiper HA (2003) Comparative safety assessment for biotech crops. Trends Biotechnol. 21: 439-444

König A, Cockburn A, Crevel RWR, Debruyne E, Grafstroem R, Hammerling U, Kimber I, Knudsen I, Kuiper HA, Peijnenburg AACM, Penninks AH, Poulsen M, Schauzu M, Wal JM (2004) Assessment of the safety of foods derived from genetically modified (GM) crops. Food Chem. Toxicol. 42: 1047-1088

Krayer von Krauss MP, Casman EA, Small MJ (2004) Elicitation of expert judgments of uncertainty in the risk assessment of herbicide-tolerant oilseed rape crops. Risk Anal. 24: $1515-1527$

Lassen J, Jamison A (2006) Genetic technologies meet the public: the discourses of concern. Sci. Tech. Human Values 31: $8-28$

Lassen J, Madsen KH, Sandøe P (2002) Ethics and genetic engineering - lessons to be learned from GM foods. Bioprocess Biosyst. Eng. 24: 263-271

Lezaun J (2006) Creating a new object of government: making genetically modified organisms traceable. Soc. Stu. Sci. 36: 499-531

Levidow L (2001) Precautionary uncertainty: regulating GM crops in Europe. Soc. Stu. Sci. 31: 842-874

Levidow L (2006) EU agbiotech regulation. Soziale Technik 3: $10-12$

Levidow L, Bijman J (2002) Farm inputs under pressure from the European food industry. Food Policy 27: 31-45

Levidow L, Boschert $\mathbf{K}$ (in press) Coexistence or contradictions? Agricultural biotechnology versus alternative agricultures in Europe. Geoforum

Levidow L, Carr $\mathbf{S}$ (in press) Europeanising advisory expertise: the role of 'independent, objective and transparent' scientific advice in agri-biotech regulation. Environ. Plann. $C$

Levidow L, Carr S, Wield D (2005) European Union regulation of agri-biotechnology: precautionary links between science, expertise and policy. Sci. Public Policy 32: 261-276

Levidow L, Murphy J, Carr S (2007) Recasting "substantial equivalence": transatlantic governance of GM food. Sci. Tech. Human Values 32: 26-64

Lheureux K, Menrad K (2004) A decade of European fields trials with genetically modified plants. Environ. Biosafety Res. 3: $99-107$

Lilley AK, Bailey MJ, Cartwright C, Turner SL, Hirsch PR (2006) Life in earth: the impact of GM plants on soil ecology? Trends Biotechnol. 24: 9-14
Lusk JL, Traill WB, House LO, Valli C, Jaeger SR, Moore M, Morrow B (2006) Comparative advantage in demand: experimental evidence of preferences for genetically modified food in the United States and European Union. J. Agr. Econ. 57: $1-21$

Madsen KH, Sandøe P (2005) Ethical reflections on herbicideresistant crops. Pest Manag. Sci. 61: 318-325

Marris C, Wynne B, Simmons P, Weldon S (2001) Public perception of agricultural biotechnologies in Europe. Final report of the PABE research project, http://www.lancs.ac.uk/depts/ieppp/pabe/

Marris C, Joly PB, Ronda S, Bonneuil C (2005) How the French GM controversy led to the reciprocal emancipation of scientific expertise and policy making. Sci. Public Policy 32: 301-308

Marvier M, Van Acker RC (2005) Can crop transgenes be kept on a leash? Front. Ecol. Environ. 3: 99-106

Mayer S, Stirling A (2002) Finding a precautionary approach to technological developments - lessons for the evaluation of GM crops. J. Agric. Environ. Ethics 15: 57-71

Mepham B (2000) A framework for the ethical analysis of novel foods: the ethical matrix. J. Agric. Environ. Ethics 12: $165-176$

Millstone E, Brunner E, Mayer S (1999) Beyond 'substantial equivalence'. Nature 401: 525-526

Miraglia M, Berdal KG, Brera C, Corbisier P, Holst-Jensen A, Kok EJ, Marvin HJP, Schimmel H, Rentsch J, van Rie JPPF, Zagon J (2004) Detection and traceability of genetically modified organisms in the food production chain. Food Chem. Toxicol. 42: 1157-1180

Mitchell P (2003) Europe sees sharp decline in GMO research. Nat. Biotechnol. 21: 468-469

Murphy J, Levidow L, Carr S (2006) Regulatory standards for environmental risks: understanding the US-European Union conflict over genetically modified crops. Soc. Stu. Sci. 36: 133-160

Myhr AI, Traavik T (2003) Sustainable development and Norwegian genetic engineering regulations: applications, impacts and challenges. J. Agric. Environ. Ethics 16: 317-335

Nielsen L, Faber BA (2002) Ethical principles in European regulation of biotechnology - possibilities and pitfalls, http://www.biotik.dk/myndigheder/bioTIK/Udredninger/ etiske_principper/engelsk/

Nisbet MC, Huge M (2006) Attention cycles and frames in the plant biotechnology debate - managing power and participation through the press/policy connection. Harv. Int. J. PressPol. 11: 3-40

Noussair C, Robin S, Ruffieux B (2004) Do consumers really refuse to buy genetically modified food? Econ. J. 114: 102120

Nowotny H (2003) Democratising expertise and socially robust knowledge. Sci. Public Policy 30: 151-156

Oreszczyn S (2005) GM crops in the UK: precaution as process. Sci. Public Policy 32: 317-324

Paula $\mathbf{L}$, van den Belt $\mathbf{H}$ (in press) Work package 5: ethics in food technologies. The institutionalisation of ethics in science policy; practices and impact, http://www.bioethics.it/pdf/ pc_3/ines_pagina_introduttiva.pdf 


\section{Societal concerns and EU regulatory frame on GM crops}

Petersen A (2005) The metaphors of risk: biotechnology in the news. Health Risk Soc. 7: 203-208

Robinson RA, Sutherland WJ (2002) Post-war changes in arable farming and biodiversity in Great Britain. J. Appl. Ecol. 39: $157-176$

Saji H, Nakajima N, Aono M, Tamaoki M, Kubo A, Wakiyama S, Natase Y, Nagatsu M (2005) Monitoring the escape of transgenic oilseed rape around Japanese ports and roadsides. Environ. Biosafety Res. 4: 217-222

Sandin P (1999) Dimensions of the precautionary principle. Hum. Ecol. Risk Assess. 5: 889-907

Sanvido O, Widmer F, Winzeler M, Bigler F (2005) A conceptual framework for the design of environmental postmarket monitoring of genetically modified plants. Environ. Biosafety Res. 4: 13-27

Schenkelaars P (2002) Rethinking substantial equivalence. Nat. Biotechnol. 20: 119

Schibeci R, Harwood J, Dietrich H (2006) Community involvement in biotechnology policy? The Australian experience. Sci. Comm. 27: 429-445

Schiemann J (2003) Co-existence of genetically modified crops with conventional and organic farming. Environ. Biosafety Res. 2: 213-217

Schot J (2001) Towards new forms of participatory technology development. Techn. Anal. Strat. Manage. 13: 39-52

SCP (2001) Opinion of the Scientific Committee on Plants concerning the adventitious presence of GM seeds in conventional seeds, http://ec.europa.eu/comm/food/fs/sc/scp/out93_ gmo_en.pdf

Shaw A (2002) "It just goes against the grain." Public understandings of genetically modified (GM) food in the UK Public Underst. Sci. 11: 273-291

Siegrist M (2000) The influence of trust and perceptions of risks and benefits on the acceptance of gene technology. Risk Anal. 20: 195-203

Slovic P (1987) Perception of risk. Science 236: 280-285
Spence A, Townsend E (2006) Examining consumer behavior toward genetically modified (GM) food in Britain. Risk Anal. 26: $657-670$

Streiffer R, Hedemann T (2005) The political import of intrinsic objections to genetically engineered food. J. Agric. Environ. Ethics 18: 191-210

Streiffer R, Rubel A (2004) Democratic principles and mandatory labelling of genetically modified food. Pub. Affairs Quart. 18: 223-248

Tencalla F (2006) Science, politics and the GM debate in Europe. Regul. Toxicol. Pharmacol. 44: 43-48

Townsend E (2006) Affective influences on risk perceptions of, and attitudes toward, genetically modified food. J. Risk Res. 9: $125-139$

van den Eede G, Aarts H, Buhk HJ, Corthier G, Flint HJ, Hammes W, Jacobsen B, Midtvedt T, van der Vossen J, von Wright A, Wackernagel W, Wilcks A (2004) The relevance of gene transfer of food and feed derived from genetically modified (GM) plants. Food Chem. Toxicol. 42: 11271156

Verhoog H, Matze M, Lammerts Van Bueren E, Baars T (2003) The role of the concept of the natural (naturalness) in organic farming. J. Agric. Environ. Ethics 16: 29-49

Vogel G (2006) Tracing transatlantic spread of GM rice. Science 313: 1714

Wandall B (2004) Values in science and risk assessment. Toxicol. Lett. 152: 265-272

Weighardt F (2006) European GMO labeling thresholds impractical and unscientific. Nat. Biotechnol. 24: 23-25

Wynne B (2001) Expert discourses of risks and ethics on genetically manipulated organisms: the weaving of public alienation. Notizie di Politeia 17: 51-76

Yoshimura Y, Beckie HJ, Matsuo K (2006) Transgenic oilseed rape along transportation routes and port of Vancouver in western Canada. Environ. Biosafety Res. 5: 67-75 